\title{
Balancing agricultural and hydrologic risk in farming systems of the Chaco plains
}

\author{
Raúl Giménez ${ }^{1, *}$, Jorge L. Mercau ${ }^{1}$, Javier Houspanossian $^{1}$ and Esteban G. Jobbágy ${ }^{1}$ \\ Affiliation: ${ }^{1}$ Grupo de Estudios Ambientales - IMASL, Universidad Nacional de San \\ Luis \& CONICET. Ejército de los Andes 950, D5700HHW. San Luis, Argentina. \\ * Corresponding author: Raúl Giménez, Tel: +54-266-4520325 (3038), e-mail: \\ gimenezgea@gmail.com
}

\begin{abstract}
Like in other semiarid areas of the world, farming systems in semiarid Chaco tend to use water-conservative crop systems to minimize production risks associated to water stress. While this strategy aims to stabilize crop yields and farmers income, the underutilization of water resources in wet years may result in heavy deep drainage water losses which could potentially lead to the development of dryland salinity. Conversely, more intensive crop systems that consume water exhaustively present lower drainage rates but are more prone to crop failure. We employed a monthly soil water balance approach to analyze the productive and ecohydrologic effects of five different farming systems across the region (winter, spring, summer, late-summer and a winter-summer double crop system) and to assess the possibility of minimizing emerging trade-offs between them through flexible water-informed cropping sequences. Our results indicate that water stress diminishes as crop systems are delayed towards the rainy season (winter $>$ spring $>$ summer $>$ late-summer), but the productively safer late-summer strategy is the one with highest drainage rates. In most of the region, the relatively high production risk and insignificant drainage probability generally determine the convenience of conservative late-summer systems. However, in areas (or years) with higher amount and/or seasonality of rainfall, more intensive double-crop systems are
\end{abstract}


necessary to minimize the likely high drainage fluxes. As rainfall is highly variable from one year to the other, the knowledge of soil water content at the onset of the season is useful to predict part of the available water offer and to asses expected production and ecohydrologic risks. In the most drainage-prone areas the implementation of flexible sequences that alternate conservative and intensive crop systems depending on soil water status, significantly reduced mean annual drainage with an acceptable increase in mean water stress index.

Keywords: semiarid Chaco; agriculture; water stress; deep drainage; crop rotation; flexible sequences

\section{Introduction}

Farming systems have to yield food, feed, fiber and/or fuel products while protecting the environment and ensuring their long term sustainability (Connor, et al., 2011). Water is the major driver of plant productivity in dryland agricultural systems of arid and semi-arid regions but it also represents a potential threat to their sustainability when it is misused (Asbjornsen, et al., 2008). In those regions, where water availability is both limited and highly variable, farmers typically apply water-conservative farming systems and low-cost management practices to minimize the productive and financial risk of crop loss in dry years (Sadras et al., 2003; Connor et al., 2011). This type of strategies intends to stabilize crop yields and ensure a minimum and safe profit to the farmer at the cost of increasing unproductive water losses in wet years (Sadras and Roget, 2004). Besides the losing opportunity of high productive output in wet years, the "excess water" generated when available water resources are underutilized may cause detrimental environmental outcomes such as erosion, flooding or dryland salinization 
(Sadras et al., 2003; Sadras and Roget, 2004; Asbjornsen, et al., 2008). These outcomes could be partially prevented by applying more intensive (and profitable) cropping systems, which use exhaustively water resources when availability is high (Keating, et al., 2002; Díaz-Ambrona, et al., 2005; Salado-Navarro and Sinclair, 2009). So, in this sense, the implementation of flexible systems that alternate conservative and intensive cropping schemes, depending on expected water availability, could contribute to both productive and environmental objectives (Tanaka, et al., 2002; Hanson, et al., 2007). So far, increasing world population demand for agricultural products has been supplied by both extensification (i.e. the addition of new cropped areas on arable lands generally replacing natural ecosystems) and intensification (i.e. more production per unit area of land already used for agriculture) of farming systems (Gregory et al., 2002). In SouthAmerican semiarid-Chaco, which presents one of the highest deforestation rates of the world, the former process accounts for most of the growth in agricultural production of the last decades (Grau, et al., 2005; Boletta, et al., 2006; Volante et al., 2012). Nearly $13 \mathrm{M}$ hectares of dry forest have been cleared for agricultural and grazing purposes, mainly dryland soybean production, and there still remain 38M hectares potentially suitable for agriculture in the region (Houspanossian, et al., submitted this issue). These broad-scale land cover changes may affect the provision of essential ecosystem services such as erosion control or water regulation (Volante, et al., 2012). Although there is crescent concern about the sustainability of current farming systems in the region (Boletta, et al., 2006; Recatalá Boix and Zinck, 2008a; Caviglia and Andrade, 2010; Volante, et al., 2012; Caviglia, et al., 2013), agricultural expansion is likely to continue in areas which are often environmentally more fragile and less productive than typical agricultural land (Recatalá Boix and Zinck, 2008a; Calviño and Monzon, 2009). 
One of the expected environmental consequences of massive replacement of native vegetation with annual crops is a disruption in the hydrological cycle and water balance (Hatton and Nulsen, 1999; Jobbágy et al., 2008; Santoni, et al., 2010; Nosetto, et al., 2012). Native dry forest make an exhaustive evapotranspirative use of rainfall generating little runoff and null deep drainage flux as evidenced by relatively dry soil profiles with high chloride accumulation underneath the vegetation (Jobbágy, et al., 2008; Santoni, et al., 2010; Amdan, et al., 2013). They are composed by a diversity of species with deep root systems and perennial life cycle which sustain water consumption for long periods. On the contrary, agricultural crops generally present shorter (annual) lifecycles, shallower root systems and often relies on soil water storing during fallow periods to supply crop water demands (Jobbágy, et al., 2008). As a consequence, water use in cropping systems is less than that of the original natural vegetation, and the excess water can be lost in the form of deep drainage below the root zone (Pannell, 2001; Keating, et al., 2002). In the semiarid plains of W and SE Australia, the replacement of native vegetation by European settlers with waterconservative farming systems based on low-input cereal crops and long fallow periods (i.e. up to 18 months), has lead to a gradual but steady rise in regional watertable levels and to the mobilization of high amounts of salt accumulated and stored in the soil profile for millennia towards the soil surface (George et al., 1997). This process resulted in large-scale secondary salinisation of land and water resources affecting 5.7M ha many decades later (National Land and Water Resources Audit, 2001). Nowadays dryland salinity is recognized as one of the most serious environmental and resource management problems in the country (Pannell, 2001).

Although the ecohydrologic consequences of current farming systems in the Chaco plains had not been thoroughly assessed yet, recent evidences indicate that at least some 
areas in the region are potentially prone to dryland salinity (Nitsch, 1995; Santoni, et al., 2010; Jayawickreme, et al. 2011; Amdan, et al., 2013). In order to preserve the potential and sustainability of agricultural production in the region, more intensive farming systems aimed to reduce drainage rates need to be employed in those areas with higher risk (Díaz-Ambrona, et al., 2005). Although a great deal of variability in rainfall, evapotranspiration, crop yields and deep drainage is expected for the semi-arid Chaco in both the spatial and temporal dimensions (Kropff, et al., 2001; Calviño and Monzon, 2009; Houspanossian et al., submitted this issue), little work has been done to explore which are the most suitable and productive farming practices for the region not to mention which could be their potential ecohydrologic outcomes. In this sense, sciencebased mathematical models and computer simulation provide useful and objective tools to analyze both, the performance of different farming systems and the potential biophysical consequences of resource management options at regional scale (Kropff et al., 2001; Bah, et al., 2009). So, the aims of this work are to simulate and analyze the productive and hydrological effects of different farming strategies in semi-arid Chaco, and to assess the possibility of minimizing emerging trade-offs between productive and environmental objectives through the implementation of flexible and "water stockinformed" cropping sequences.

Firstly, a monthly-step soil-water balance model is used in the whole region to address the effect of different farming systems on productive and ecohydrologic risks in the spatial dimension (30’x 30' spatial resolution). Then, the analysis focuses on 4 or 5 contrasting locations and the most important crop systems to address the temporal dimension in drainage variability, and to relate production and drainage risks to the initial soil water condition. Finally, the possibility of reducing both production and hydrological risks across the region, through flexible cropping sequences that alternate 
conservative and intensive cropping systems based on initial soil water content is discussed.

\section{Materials and methods}

\subsection{Description of the study region}

The semi-arid Chaco region is a vast sedimentary plain of over $65 \mathrm{M}$ hectares in the north-central part of Argentina, east of Bolivia and the western part of Paraguay (Olson, et al., 2001; Fig. 1). The ecoregion presents a monsoonal climate with strong seasonality (dry winters, rainy summers) that increases from east to west (Riveros, 2003). Annual rainfall is highly variable in the region, from $500 \mathrm{~mm}_{\text {.year }}^{-1}$ in the center to $1000 \mathrm{~mm}_{\text {.year }}{ }^{-1}$ in the eastern and western extremes. Mean annual temperature increases from south to north, varying from $18^{\circ} \mathrm{C}$ to $21^{\circ} \mathrm{C}$ (Minetti, 1999). The months with highest temperature, January and February, coincide with those of maximum rainfall. Dominant soils of the region are deep without physical impediments to root growth, predominantly of loamy textures with a slight textural gradient from west (coarser) to east (smoother). The watertable is generally deep and highly saline. Fertility in general is high (Riveros, 2003).

The predominant native vegetation is xerophytic deciduous forest with patches of grassland (Boletta, et al., 2006). The region presents variable agricultural potential where water availability is the main limiting factor for crop production (Riveros, 2003). Main deforested areas are located in northwest Argentina in the wetter parts of Salta, Tucuman and Santiago del Estero provinces, and in Boqueron department in western Paraguay. In Argentina, forests were converted mainly to agriculture, while in Paraguay they were converted to pastures (Clark, et al., 2010). Soybean is the dominant crop in 
Argentinean Chaco while maize, wheat, sunflower and sorghum are grown in lesser extent. Other crops like cotton or dry beans have a high local importance in some areas. In Paraguay, Panicum maximum cv Gatton and Cenchrus ciliaris are the most cultivated grasses for intensive beef production. In lesser extent, sorghum, cotton and groundnuts are the main crops grown (Glatzle and Stosiek, 2002). Farming systems of Bolivia represent a very reduced but expanding area in the NW corner of our region of study. Soybean is the main crop sown extensively in the fertile plain of Santa Cruz east of the Andes (Recatalá Boix and Zinck, 2008a).

\section{- Insert Figure 1 here -}

\subsection{The water balance model}

A simple monthly soil-water balance model was developed to simulate the spatiotemporal variation of productive risks and hydrological variables of different crop systems across the semi-arid Chaco. Crop systems basically include five sowing dates which differ in their temporal patterns of evapotranspiration during the growing season: winter (W), spring (Sp), summer (S), late summer (LS) and double-crop systems (DC), which include a summer crop after a winter crop in the same growing season. All of these systems are or have been common cropping practices in the region: winter cereals such as wheat or barley sown in May to June (W); sunflower or early sown maize sown in August (Sp); maize or soybean crops sown in late November to early December (S) or in early January (LS); and wheat-soybean or wheat-maize double crop systems (DC). The model is mainly based on FAO (Food and Agriculture Organization) research (Allen, et al., 1998). Soil water availability for crop evapotranspiration (AW) is 
computed every month by adding water gains (i.e. precipitation) and deducing water losses (i.e. runoff, evapotranspiration and deep percolation) from soil $\mathbf{A W}$ of the previous month (Eq. 1)

$$
A W_{i}=A W_{i-1}+P_{i-1}-R_{i-1}-E T_{i-1}-D_{i-1}
$$

Where $\mathbf{A} \mathbf{W}_{\mathbf{i}}$ and $\mathbf{A} \mathbf{W}_{\mathbf{i}-1}$ are the soil available water $(\mathrm{mm})$ at the beginning of the month $\mathrm{i}$ and of the previous month, respectively; $\mathbf{P}_{\mathbf{i}-1}$ is precipitation $(\mathrm{mm}), \mathbf{R}_{\mathbf{i}-1}$ is runoff $(\mathrm{mm})$, $\mathbf{E T}_{\mathbf{i}-\mathbf{1}}$ is actual evapotranspiration (or evaporation during fallows) and $\mathbf{D r} \mathbf{r}_{\mathbf{i}-\mathbf{1}}(\mathrm{mm})$ is deep drainage of the previous month, respectively. AW was allowed to range from zero to a maximum value $\left(\mathbf{A} \mathbf{W}_{\max }\right)$ defined by the soil water-holding capacity (determined mainly by soil texture and organic matter content) and by crops maximum rooting depth (see section 2.2.2.1 for further details).

The term $[\mathbf{P}-\mathbf{R}]$ in Eq.1 is the effective precipitation $\left(\mathbf{P}_{\text {eff }}\right)$ and represents the amount of rainfall that effectively enters the soil after substracting surface runoff water losses. $\mathbf{P}_{\text {eff }}$ can also be computed as a function of monthly rainfall (Eq.2). Equation 2 resulted from fitting the monthly integration of daily runoff computed with a pre-existent model developed in the region (Dardanelli, et al., 2010), to monthly integrated daily rainfall data of 41 years from six weather stations across the region $\left(2^{\text {nd }}\right.$ order polynomial model; $\mathrm{r}^{2}=0.97 ; \mathrm{n}=2952$ ). According to this model, as monthly rainfall increases $\mathbf{P}_{\text {eff }}$ increases with a declining rate as runoff water losses increase exponentially.

$$
P_{\text {eff }}(\mathbf{m m})=1.14+0.86 * P-0.0007 * P^{2}
$$


Actual evapotranspiration (or soil evaporation when there is no crop), ET, was computed by multiplying crop reference evapotranspiration $\left(\mathbf{E} \mathbf{T}_{\mathbf{0}}\right)$, which depends on local weather conditions, by a crop coefficient $(\mathbf{K c})$ that accounts for differences in crop/fallow cover characteristics (Eq. 3)

$\mathbf{E T}=\mathbf{E T}_{\mathbf{0}} * \mathbf{K c}$

Where ET is actual evapotranspiration (mm.month $\left.{ }^{-1}\right), \mathbf{E T}_{\mathbf{0}}$ is crop reference evapotranspiration (mm.month ${ }^{-1}$ ) and $\mathbf{K c}$ is crop coefficient (unitless). Monthly $\mathbf{E T}_{\mathbf{0}}$ was computed from a climate database for the region (see section 2.2.2.1 for further details). For the relevant crops of this study, Kc varies spatio-temporally from 0.1 to 1.15 , depending on the crop system and its stage of development during crop growing season, and on $\mathbf{E T}_{\mathbf{0}}$ and size and frequency of rainfall events during fallows (see section 2.2.2.2 for further details).

Deep drainage (Dr) is a residue of the soil-water balance that only occurs when computed $\mathbf{A W}$ surpasses the maximum soil water-holding capacity $\left(\mathbf{A} \mathbf{W}_{\mathbf{m a x}}\right)$. When the soil matrix is plenty, the water in excess is lost below the root zone in the form of deep drainage (Eq. 4) and cannot be used for crop transpiration neither in the current nor in the subsequent months.
Dr $=0$
when $\mathrm{AW}_{\max }>\left(\mathrm{AW}_{\mathrm{i}-1}+\mathrm{P}_{\text {eff }}-\mathrm{ET}\right)$
Dr $=\left(\mathrm{AW}_{\mathrm{i}-1}+\mathbf{P}_{\mathrm{eff}}-\mathbf{E T}\right)-\mathbf{A} \mathbf{W}_{\max }$
when $\mathrm{AW}_{\max }<\left(\mathrm{AW}_{\mathrm{i}-1}+\mathrm{P}_{\mathrm{eff}}-\mathrm{ET}\right)$

\subsubsection{Crop stress}


Crop performance was computed with a Water Stress Index (WSI) that considered the ratio between water availability for actual ET (offer) and potential ET (demand) during the most critical period for yield determination (CPY) of each crop system (Eq. 5). Implicit in this computation is the concept that there is an ontogenic critical period in which any restriction to crop growth affects directly grain yield, while crop stress in other periods have considerably less consequences (Nix and Fitzpatrick, 1969). Water offer for actual evapotranspiration was computed as the addition of available soil water $\left(\mathbf{A} \mathbf{W}_{\mathbf{C P Y}}\right)$ and effective rainfall during critical period months $\left(\mathbf{P}_{\text {effCPY }}\right)$, while potential demand was computed as the sum of ET during the same period $\left(\mathbf{E T} \mathbf{T}_{\mathbf{C P Y}}\right)$.

WSI = 0

$\mathbf{W S I}=\underline{\mathbf{E T}}_{\mathbf{C P Y}}-\left(\underline{\mathbf{P}}_{\text {eff }}^{\mathrm{CPY}}+\underline{\mathbf{A W}} \underline{\mathrm{CPY}}^{*}\right)$ when $\mathrm{ET}_{\mathrm{CPY}}<\left(\mathrm{P}_{\mathrm{eff}} \mathrm{CPY}+\mathrm{AW}_{\mathrm{CPY}}{ }^{*}\right)$

when $\mathrm{ET}_{\mathrm{CPY}}>\left(\mathrm{P}_{\text {eff } \mathrm{CPY}}+\mathrm{AW}_{\mathrm{CPY}} *\right)$

\section{$\mathbf{E T}_{\mathbf{C P Y}}$}

The asterisk in the $\mathbf{A} \mathbf{W}_{\mathbf{C P Y}}$ term of Equation 5 stands for an adjustment in soil available water use. As crop transpiration is affected as soil water is depleted (Sinclair, 2005), a restriction to crop $\mathbf{A W}$ use was applied for low $\mathbf{A W}$ values. In the model, potential demand is firstly supplied by effective rainfall and then by $\mathbf{A W}$ when $\mathbf{P}_{\text {eff }}$ is insufficient. However, crops cannot use all AW with the same efficiency: as the soil dries transpiration rate remains constant and maximum until a threshold soil-water content is reached, and thereafter, it declines linearly (Ray, et al., 2002). So, a bi-linear model was employed to adjust AW: no restriction was imposed when crops use water between field capacity and a threshold $\mathbf{A W}$ of $40 \%$ of total transpirable water (i.e. $\left.\mathbf{A} \mathbf{W}_{\mathbf{t}}=\mathbf{A} \mathbf{W}_{\max }{ }^{* 0.4}\right)$; below this threshold, ability to use soil water declines linearly from $100 \%$ to zero in the lower limit (Eq. 6) 


$$
\begin{array}{ll}
\mathbf{A} \mathbf{W}_{\mathbf{C P Y}} * \mathbf{A W} & \text { for } \mathrm{AW}>\mathrm{AW}_{\mathrm{t}} \\
\mathbf{A} \mathbf{W}_{\mathbf{C P Y}} * \mathbf{A W} * \mathbf{A W} / \mathbf{A W} & \text { for } \mathrm{AW}<\mathrm{AW}_{\mathbf{t}}
\end{array}
$$

\subsubsection{Input parameters}

\subsubsection{Meteorological data and soil parameters}

Monthly weather data (1959-2002) gridded at 30'latitude by longitude resolution was obtained from the Climatic Research Unit (CRU) website (New, et al., 2002). Specifically, monthly rainfall $(\mathbf{P})$ and reference evapotranspiration $\left(\mathbf{E T}_{\mathbf{0}}\right)$ computed from meteorological data according to the FAO-Penmann Monteith equation (Allen, et al., 1998), were employed as climatic inputs for the soil-water balance model. In addition, independent daily rainfall datasets (1971-2012) from six stations in the region (Mariscal Estigarribia: 22.0S 62.6W; Las Lajitas: 24.4S 64.1W; Las Lomitas: 24.4S 60.4W, Las Breñas: 27.1S 67.1W; Santiago del Estero: 27.5S 64.2W and Bandera: 28.9S $62.3 \mathrm{~W}$ ) were employed as supplementary information to characterize rainfall structure (mean size and frequency of wetting events) which was necessary for runoff and fallow evaporation computations.

Similar soil parameters were used for most of thestudy region. Maximum soil water availability to support plant transpiration $\left(\mathbf{A W}_{\max }\right)$ was set at $234 \mathrm{~mm}$, as the result of setting soil profile depth to $1,8 \mathrm{~m}$ (Dardanelli, et al., 1997) and soil water-holding capacity between the drained upper limit and the permanent wilting point for the textural range of the dominant soils (sandy loam to clay), at $130 \mathrm{~mm} \cdot \mathrm{m}^{-1}$ (Sinclair, 2005). The only exception considered was a relatively small area in the BoliviaParaguay border (specifically, in 20S 62W, 20.5S 62W, 21S 62W and 21S 61.5W), 
where the low soil water-holding capacity of the sand to loamy sand soils (i.e. $100 \mathrm{~mm} \cdot \mathrm{m}^{-1}$, Sinclair, 2005) determine a lower $\mathbf{A} \mathbf{W}_{\max }$ (i.e. $\left.180 \mathrm{~mm}\right)$. Other soils types with different water-holding characteristcs (loamy sand: $100 \mathrm{~mm} . \mathrm{m}^{-1}$ or silt loam: 150 $\mathrm{mm} \cdot \mathrm{m}^{-1}$ ) are also present in lesser extent across the region (mostly, paleo-river beds or river margins), but could not be adequately represented at the spatial scale of the analysis. Areas near the mountains, where soil rooting depth is restrictive for agriculture (i.e. leptosols), were discarded (Fig. 1). Lack of regional information on other edaphic constraints, such as high salinity/sodicity impeded further distinction among the soils of the region.

\subsubsection{Crop parameter $\mathrm{Kc}$}

For different crop systems, Kc was set according to the expected leaf area and stage of development of the corresponding crops (Table 1). Crop systems in which the critical period for yield determination would occur in January were purposely avoided in this study given that they are not currently used by local farmers, who are aware of the risk of extreme high temperature episodes and dry spells during the critical period for yield determination (Calviño and Monzón, 2009). For fallow months, Kc was computed as a function of $\mathbf{P}$ and $\mathbf{E T}_{\mathbf{0}}$ (Eq.7), according to FAO procedure for computing $\mathbf{K c}$ during the initial stage of crop development (Allen, et al., 1998)

\section{- Insert Table 1 here -}

$K c=\underline{\left(1.2 * \operatorname{EXP}\left(-0.0145 * \mathbf{E T}_{0}\right)+0.47\right) * \mathbf{P}}$

$$
\left(3.3+0.37 * \mathbf{E T}_{0}\right)+\mathbf{P}
$$




\subsection{Analysis of model outputs}

In order to analyze spatial differences in crop and drainage risks of the different crop systems across the region, the model was run for each system in sequence for the whole period (i.e. the same crop system repeated in 44 consecutive seasons). Initial soil water content $\left(\mathbf{A W}_{\text {ini }}\right)$ was set at $25 \%$ of maximum soil water availability for the first season; and the residual water content at the end of each season $\left(\mathbf{A} \mathbf{W}_{\text {res }}\right)$ was taken as $\mathbf{A} \mathbf{W}_{\mathbf{i n i}}$ input of the following season. For simulation purposes, each growing season started on 1-Jun and ended on 31-May of the following year.

Main outputs of the model analyzed were mean Water Stress Index (WSI) and mean annual Drainage (Dr). Other outputs analyzed were Water Deficit $\left(\mathbf{W D}_{\mathbf{C P Y}}=\mathbf{E T}_{\mathbf{C P Y}}\right.$ $\left.\mathbf{P}_{\text {effCPY }}\right)$ and Available Soil Water $\left(\mathbf{A} \mathbf{W}_{\mathbf{C P Y}}\right)$ during the critical period for yield determination, and Residual Soil Water Content at the end of the growing season $\left(\mathbf{A} \mathbf{W}_{\text {res }}\right)$. These outputs served to explain spatio-temporal variations in WSI and Dr. For the spatial analysis, a triangular interpolation function (QGIS development team, 2013) was employed to generate map representations of mean values (44 seasons) of WSI, Dr, $\mathbf{W D}_{\mathbf{C P Y}}, \mathbf{A} \mathbf{W}_{\mathbf{C P Y}}$ and $\mathbf{A} \mathbf{W}_{\text {res }}$ for the summer crop system (S), which has been the most widely spread across the region in the last decades. Then, $\mathbf{S}$ outputs were taken as references for later comparison to outputs of the other crop systems.

Five contrasting sites of interest (Alto Paraguay AP, Loma Plata LP, Tartagal TL, Tucumán TM and Bandera BN; Fig.1) and three crop systems (S, LS and DC) were selected for more specific analysis. In four sites, temporal variation in drainage was analyzed in relation to annual rainfall, $\mathbf{A} \mathbf{W}_{\text {ini }}$ and crop system. In the five sites, the effect of initial soil water content $\mathbf{A} \mathbf{W}_{\text {ini }}$ on mean WSI and Dr was analyzed. For this purpose, the model was modified to have the same $\mathbf{A} \mathbf{W}_{\text {ini }}$ values $(10 \%, 33 \%, 50 \%, 66 \%$ and $90 \%$ of $\left.\mathbf{A} \mathbf{W}_{\max }\right)$ in each of the 44 years. The responses of $\mathbf{W S I}$ and $\mathbf{D r}$ to $\mathbf{A} \mathbf{W}_{\mathbf{i n i}}$ 
were then employed to establish decision rules for flexible crop sequences aimed to reduce both, regional WSI and Dr, alternating conservative and intensive systems depending on $\mathbf{A} \mathbf{W}_{\text {ini. }}$

\subsection{Model sensitivity to changes in input parameters}

A sensitivity analysis was performed to evaluate the impact of variations in three input parameters, runoff, fallow evaporation and $\mathbf{A} \mathbf{W}_{\max }$, on the main outputs of the model: WSI and Dr. In a continuous summer system sequence $(\mathbf{S})$, each of these parameters was increased and reduced by $50 \%$ of the original values, and the new outputs were contrasted to those of the original model.

\section{Results}

\subsection{Spatial analysis of cropping strategies}

Marked differences were found across the semiarid Chaco in both crop production risk and hydrological outputs with different farming strategies. The computed water stress index (WSI) for a continuous summer crop strategy (S) was very high (50-60\%) in the northern part of the region (western Paraguay), but minimum towards the west of the central part (province of Salta in Argentina and its boundary with Bolivia) (Fig. 2.a). High potential evapotranspiration and low rainfall (Fig. 1) determine high water deficits (i.e. $>200 \mathrm{~mm}$ ) during the critical period for yield determination of $\mathbf{S}$ in western Paraguay (Fig. 2.b) that cannot be alleviated by the scarce water stored in the soil (i.e. $<50 \mathrm{~mm}$; Fig. 2.c). On the contrary, in the western edge of the region, the amount of water stored in the soil at the onset of the critical period is almost sufficient to fulfill the mild water deficit of $\mathbf{S}$ determining low WSI (Figs. 2.a, 2.b and 2.c). 
Mean annual drainage from $\mathbf{S}$ also presented high variability across the region (Fig. 2.d). Although null drainage was computed for most of the semiarid Chaco, high drainage $\left(20 \mathrm{~mm} \cdot \mathrm{y}^{-1}\right)$ is likely to occur towards the edges of the region, particularly in the western but also in the northern and southern edges. While null drainage occured mainly in areas with low rainfall (i.e.P<700mm), mean annual precipitation solely was not enough to explain differences in drainage in areas of higher rainfall. Other factors, like soil water status at the beginning of the season (Fig. 2.e), are also determinants of drainage propensity as will be discussed later.

\section{- Insert Figure 2 here -}

Other cropping systems showed similar regional patterns to the summer crop one (Fig. 3). As a general rule, areas with high WSI for $\mathbf{S}$ presented relatively high WSI for other cropping systems and vice versa (Fig. 3.a). Continuous winter cropping (W) was the system that presented the highest production risk across the region with WSI ranging from 0.5 to 0.9 in almost $80 \%$ of the studied area. As most of its growing cycle (including the critical period for yield determination, CPY) occurs before the rainy season, $\mathbf{W}$ is highly prone to water scarcity at the moment of yield definition. The absence of rainfall during winter and early spring determines that the high residual water left by the previous winter crop (Fig. 3.e) was gradually consumed during the growing cycle resulting in variable soil water availability at the onset of the critical period (Fig. 3.c) which would not suffice to face the very high water deficit of this period (Fig. 3.b). As rainfall predominantly occurs after the critical period and crop harvest, soil profile is normally re-filled during the rainy season leaving high residual water content for the next-season crop (Fig. 3.e). 
The opposite strategy to $\mathbf{W}$ is sowing late-summer crops (LS). LS was the safest option in terms of avoiding water stress probability during the critical period (Fig. 3.a). According to our computations, almost $50 \%$ of the semiarid Chaco can be sown with $\mathbf{L S}$ with a mean WSI $\leq 0.3$, while only $40 \%$ of the region can be sown with $\mathbf{S}$ at a similar WSI threshold (Fig. 2.a). In comparison to $\mathbf{S}, \mathbf{L S}$ allows more soil water recharge with spring-summer rainfall occurring during pre-sowing fallow and initial stages of crop development. As a result, LS presented a better soil water status at the onset of the critical period (Fig. 3.c) and also presented lower $\mathbf{W D}_{\mathbf{C P Y}}$ conditions (Fig. 3.b). The advantage of $\mathbf{L S}$ over $\mathbf{S}$ was evident in relatively wet areas of the region (WSI for $\mathbf{S} \approx 0.1-0.4$ ) but dissapeared in the driest ones (i.e. where WSI for $\mathbf{S}$ crops $>0.45$; Figs. 2.a and 3.a).

The other two crop systems, $\mathbf{S p}$ and $\mathbf{D C}$, presented some similarities to $\mathbf{W}$ and $\mathbf{S}$, respectively. To a lesser extent than for $\mathbf{W}$, Sp presented relatively high WSI across the region (i.e. $>50 \%$ in $70 \%$ of the study area; Fig. 3.a). Although the critical period of $\mathbf{S p}$ coincides with the onset of the rainy season, high $\mathbf{E T}$ determines that $\mathbf{W D}_{\mathbf{C P Y}}$ was high (i.e.100-250mm; Fig. 3.b) and could not be overcome by the scarce water stored in the soil (i.e. $<50 \mathrm{~mm}$ in most of the region; Fig. 3.c), given that the first rains of the season had been consumed during the early stages of the crop. As for DC, the only difference between the summer component of $\mathbf{D C}\left(\mathbf{D C}_{\mathbf{S}}\right)$ and $\mathbf{S}$ is that the former is sown behind a winter crop that consumed water, leaving less soil water for its critical period (Fig. 3.c). As both systems present similar $\mathbf{W D}_{\mathbf{C P Y}}$ (Fig. 3.b), WSI of $\mathbf{D C}_{\mathbf{S}}$ was slightly higher than that of $\mathbf{S}$, because of the lesser soil water content at the critical period. Water consumption by the two components of DC was higher than that of any of the other crop systems, leaving less residual water $\left(\mathbf{A} \mathbf{W}_{\text {res }}\right)$ for the next season crop (Fig. 3.e). As 
a consequence, WSI for the winter component of $\mathbf{D C}\left(\mathbf{D C}_{\mathbf{W}}\right)$ in a continuous DC sequence would be even higher than that of $\mathbf{W}$ (data not shown).

As regards to drainage $\mathbf{L S}$, the safest option in terms of minimizing WSI, was the one with the highest drainage rates (Fig. 3.d). According to our computations, if continuous LS was applied all across the semi-arid Chaco, more than $25 \%$ of the region would present mean annual drainage rates higher than $20 \mathrm{~mm} \cdot \mathrm{y}^{-1}$. The best option to minimize drainage events was the intensive DC. Except for few exceptions in the study area, continuous DC determined mean annual drainage rates $<5 \mathrm{~mm} \cdot \mathrm{y}^{-1} . \mathbf{S p}, \mathbf{S}$ and $\mathbf{W}$ represented intermediate situations. Although $\mathbf{S p}$ appears as an interesting alternative to achieve partial control of drainage, its high WSI indicate that crop yield would normally be well below its potential. From this point forward, the analysis will be centered in only three crop systems: $\mathbf{S}, \mathbf{L S}$ and DC. Sp and $\mathbf{W}$ will not be considered because of their likely high WSI, and also the high drainage risk of $\mathbf{W}$.

\section{- Insert Figure 3 here -}

\subsection{Temporal analysis of drainage events}

While our spatial analysis of drainage was focused on mean annual rates, it is important to highlight that drainage events do not distribute evenly across years but tend to be episodic. Figure 4 shows cumulative drainage for the whole sequenced period (19592002) for continuous $\mathbf{S}, \mathbf{L S}$ and DC in four contrasting sites of interest. Heavy drainage events concentrated in wet periods, when two essential conditions were met: a high water input from rainfall and a high soil water content that limits soil capacity to store additional water. This situation is more likely to occur in Tartagal (i.e. 1978-1992 wet 
period; Fig. 4.a) or Tucumán (i.e. 1977-1985 period; Fig. 4.b) than in Loma Plata, where high potential evapotranspiration (Fig. 1) determine a restrictive initial soil water content for the crop (Fig. 4.d).

During wet periods in sites prone to drainage, intensive cropping systems like DC contributed to reduce drainage risk both by increasing soil water consumption during the current growing season and by leaving less residual water in the soil for the next crop (Figs. 4.a, 4.b and 4.c). Conversely, water-conservative systems, such as LS, underused water leaving more residual water for the next crop, increasing drainage propensity (Figs. 4.a, 4.b and 4.c).

\section{- Insert Figure 4 here -}

\subsection{Productive and drainage risks in relation to initial soil water status}

Initial soil water content ( $\left.\mathbf{A} \mathbf{W}_{\mathbf{i n i}}\right)$, a parameter that can be easily measured at the onset of the growing season, can be a useful tool to evaluate both productive and drainage risks of alternative crop systems. As a general rule, as initial soil water content increases, crop water stress decreases but there is more propensity to drainage water losses (Fig. 5). This rule stands for summer (S), late-summer (LS) and the winter component of double-crop systems $\left(\mathbf{D C}_{\mathbf{W}}\right)$, but not for the second crop in $\mathbf{D C}\left(\mathbf{D C}_{\mathbf{S}}\right)$ in which WSI was relatively high and almost unaffected by $\mathbf{A} \mathbf{W}_{\text {ini }}$ due to soil water consumption of the previous crop. Changing crop system from $\mathbf{S}$ to $\mathbf{L S}$ generally resulted in lower WSI but with an increasing effect on drainage rates as $\mathbf{A} \mathbf{W}_{\text {ini }}$ increased. On the other hand, DC was the best option to minimize drainage risk. This positive effect was higher when $\mathbf{A} \mathbf{W}_{\text {ini }}$ is high, but also was higher the yield penalty of sowing a crop before a summer crop (i.e. the WSI difference between $\mathbf{S}$ and DC), so as 
the tradeoff between reducing productive risk by using $\mathbf{S}$ or using $\mathbf{D C}$ to reduce drainage.

The magnitude of expected changes in hydrologic and production risks did not only vary with $\mathbf{A} \mathbf{W}_{\text {ini }}$ but also with local environmental conditions. For instance, changing crop strategies from $\mathbf{S}$ to $\mathbf{L S}$ in relatively wet sites such as Tartagal or Tucumán increased mean annual drainage in $15-60 \mathrm{~mm}$ depending on $\mathbf{A} \mathbf{W}_{\text {ini }}$, with little or no advantage in crop yields. Moreover, even DC presented a relatively low WSI for the summer component $\left(\mathbf{D C} \mathbf{C}_{S}\right)$ but an immense effect on reducing annual drainage (i.e. up to $140 \mathrm{~mm}$ ), particularly in very high $\mathbf{A} \mathbf{W}_{\text {ini }}$ conditions (Figs. 5.d and 5.e). Conversely, in drier sites like Loma Plata where WSI were normally high and very sensitive to both $\mathbf{A} \mathbf{W}_{\text {ini }}$ and crop system variation, $\mathbf{L S}$ crops contributed to reduce the inherently high production risk, without major implications on drainage (Fig. 5.b). In this environment, drainage was negligible in almost all the $\mathbf{A} \mathbf{W}_{\text {ini }}$ gradient, being significant only when $\mathbf{A W}_{\text {ini }}$ was extremely high (i.e.90\%) which is highly unlikely (Fig. 4.d). Bandera and Alto Paraguay (Figs. 5.a and 5.c) are intermediate situations in which both, drainage and WSI were sensitive to $\mathbf{A} \mathbf{W}_{\text {ini }}$ and crop system changes, and where tradeoffs between production and hydrologic objectives were more evident.

It is worth to mention that $\mathbf{A} \mathbf{W}_{\text {ini }}$, the main source of water for $\mathbf{W}$, was insufficient to fulfill crop requirements. In sites with high potential evapotranspiration, like Loma Plata or Alto Paraguay, WSI of $\mathbf{W}$ was generally high (i.e. 0.5-0.8) even when $\mathbf{A} \mathbf{W}_{\text {ini }}$ was close to field capacity (Fig. 5a and 5.b). High WSI for $\mathbf{W}$ was also evident in other sites of interest, limiting single $\mathbf{W}$ economic feasibility only to certain locations (i.e. Bandera) when $\mathbf{A} \mathbf{W}_{\text {ini }}$ is high (Fig. 5.c). Major differences between $\mathbf{W}$ versus other crop systems were found in sites like Tartagal or Tucumán, where rainfall seasonality is higher (Fig. 5.d and 5.e). These sites were also the ones with higher drainage risk. 


\section{- $\quad$ Insert Figure 5 here -}

\subsection{Flexible crop sequences for balancing production and hydrologic tradeoffs}

Significant reductions in both WSI and drainage can be achieved by the implementation of flexible crop sequences that alternate conservative and intensive crop systems in response to a water status indicator such as $\mathbf{A} \mathbf{W}_{\text {ini. }}$. As trade-offs between WSI and Dr differed among locations (Fig. 5) because of their amount and distribution of rainfall, different decision rules were established $a d$ hoc for 3 distinct subzones: A, relatively dry areas $\left(\mathrm{PP}<650 \mathrm{~mm} \mathrm{yr}^{-1}\right) ; \mathbf{B}$, intermediate rainfall areas or high-rainfall areas with mild seasonality (P 650-800mm.yr ${ }^{-1}$ or $\mathrm{P}>800$ with seasonality<0.66) and $\mathbf{C}$, highrainfall areas with strong seasonality $(\mathrm{P}>800$ and seasonality $>0.66)$. For the purposes of this study, seasonality was computed as the ratio between the December-to-March rainfall and the rainfall of the whole growing season (June to May). For most of the region (subzone B), three alternative crop systems were considered at the initiation of each year: $\mathbf{S}, \mathbf{L S}$ and $\mathbf{D C}$. In years with low initial soil water content $\left(\mathbf{A W}_{\mathbf{i n i}}<120 \mathrm{~mm}\right)$ water-conservative $\mathbf{L S}$ was employed to face likely high WSI; in years in which soil condition was initially wet $\left(\mathbf{A W}_{\mathbf{i n i}}>160 \mathrm{~mm}\right)$ intensive $\mathbf{D C}$ was chosen to prevent high drainage events; and when soil water condition was moderate (AW $\mathbf{W}_{\text {ini: }}$ 120-160mm), intermediate $\mathbf{S}$ system was employed to seek both, mild WSI and low drainage rates. Similar concepts were employed for decision rules for the other subzones of the region where the management of one of the two risks, production or ecohydrologic, was locally more important than that of the other. In subzone A, where WSI is generally high and drainage risk is very reduced, $\mathbf{L S}$ was the preferred crop system unless $\mathbf{A} \mathbf{W}_{\text {ini }}$ was unusually high $\left(\mathbf{A} \mathbf{W}_{\text {ini }}>160 \mathrm{~mm}\right)$ in which case more water consuming $\mathbf{S}$ crops were 
sown to reduce drainage risk; In subzone $\mathbf{C}$, which is more prone to drainage and where WSI is relatively low, DC was priorized to control drainage and $\mathbf{S}$ was employed only when initial water availability was low $(<100 \mathrm{~mm})$.

The simulation of flexible sequences according to the decision rules established resulted in an overriding proportion of $\mathbf{L S}$ sown in subzones $\mathbf{A}$ and $\mathbf{B}$ (i.e. a 43-year mean of $99 \%$ and $90 \%$ of the area in $\mathbf{A}$ and $\mathbf{B}$ respectively) and an important proportion of $\mathbf{S}$ crops sown in subzone $\mathbf{C}$ (i.e. $76 \%$ ). Intensive DC systems were sown in $24 \%$ of the subzone $\mathbf{C}$ and only in $4.4 \%$ of the subzone $\mathbf{B}$. Considering the relative area that represents each of the three subzones analyzed (i.e.33, 46 and $21 \%$ of the semi-arid Chaco, for A, B and C, respectively), the relative presence of $\mathbf{S}, \mathbf{L S}$ and $\mathbf{D C}$ in the flexible sequence performed across the region was $19 \%, 74 \%$ and $7 \%$, respectively.

The rotation of crop systems with different water use capabilities (S, LS and DC) depending on initial soil water status, resulted in a reduction of mean regional WSI from 0.33 under continuous $\mathbf{S}$ to 0.29 in the flexible crop sequence (Fig. 6.a) and a reduction in mean annual drainage from 6.7 to $2.5 \mathrm{~mm}^{-1} \mathrm{y}^{-1}$ (Fig. 6.b). Most significant reductions in WSI were obtained in subzones $\mathbf{A}$ and $\mathbf{B}$, in sites where mean WSI for $\mathbf{S}$ $<0.5$ (Fig. 6.a). As a result, the area with WSI $<0.3$ increased from $40 \%$ under continuous $\mathbf{S}$ to $54 \%$ of the study area with the flexible sequence. A slight increase in WSI was allowed in subzone $\mathbf{C}$ (Fig. 6.a) to achieve significant reductions in drainage, particularly in those sites in which $\mathbf{S}$ presented very high drainage rates (i.e. >100 mm. ${ }^{-}$ ${ }^{1}$; Fig. 6.b).

\section{- $\quad$ Insert Figure 6 here -}




\subsection{Model sensitivity analysis}

Variations in runoff (Figs. 7.a and 7.d) and fallow evaporation (Figs. 7.b and 7.e) markedly modified main model outputs: water stress (WSI) and drainage (Dr). Conversely, significant modifications in maximum soil water availability $\left(\mathbf{A} \mathbf{W}_{\max }\right)$ only resulted in very slight changes in both outputs (Figs. 7.c and 7.f). Reducing runoff water losses by $50 \%$, reduced mean regional water stress for $\mathbf{S}$ from 0.33 in the original model, to 0.22 with an increase in the area with $\mathbf{W S I}<0.3$ from $40 \%$ in the original model, to $69 \%$ of the study area (Fig. 7 .a). On the other hand, a $50 \%$ increase of runoff resulted in a mean regional water stress of 0.45 and an area with $\mathbf{W S I}<0.3$ of only $14 \%$ of the study area. Similarly to what was found for runoff, reducing fallow evaporation water losses resulted in a mean regional water stress for $\mathbf{S}$ of 0.21 and $72 \%$ of the area with WSI $<0.3$ (Fig. 7.b). However, a 50\% increase in fallow evaporation had less effect than that of runoff, resulting in a mean WSI of 0.38 and an area with WSI $<0.3$ of $26 \%$. Effects of increasing evaporation were observed mainly in the range of 0 to 0.35 of original WSI. Contrary to what was expected, variations in $\mathbf{A} \mathbf{W}_{\mathbf{m a x}}$ had a minimal effect on WSI (Fig. 7.c).

As regards to drainage, a 50\% decrease in either runoff or fallow evaporation increased significantly deep drainage water flux. This effect increased as mean annual drainage of the original model increases, reaching values higher than $200 \mathrm{~mm} \cdot \mathrm{y}^{-1}$ in the most extreme cases (Figs. 7.d and 7.e). On the contrary, increasing water losses via runoff or fallow evaporation almost nullified deep drainage fluxes. Only in the most extreme cases, significant drainage rates $<30 \mathrm{~mm} . \mathrm{y}^{-1}$ were detected. As observed for water stress, modifying $\mathbf{A} \mathbf{W}_{\max }$ had almost no effect on computed mean annual drainage (Fig. 7.f). 


\section{- Insert Figure 7 here -}

\section{Discussion}

Agricultural production and ecohydrologic risks display a strong variation in the semiarid Chaco not only in response to climatic gradients, but more importantly as a result of the selection of crop seasonality. As a general pattern, the monsoonal climate dictates that crop production risk decreases as crop systems are delayed towards the rainy season. This strategy aims to stock water in the soil profile for later supply during crop growth and to situate the most critical phenological stages for yield determination in periods with relatively mild environmental conditions (Calviño and Monzón, 2009). Although this general rule is advisable for most of the region, in areas with relatively high rainfall and/or seasonality (like the western boundary of the region) the use of water-conservative crop systems increases the probability of water surplus losses in the form of deep drainage, that may affect the long-term sustainability of farming systems through the development of dryland salinity (Amdan, et al., 2013). Deep drainage water losses, in turn, can be efficiently controlled by applying more intensive crop systems, which suppose higher immediate production risks. Local (and temporal) differences in rainfall amount and seasonality, together with annual evapotranspiration, will ultimately define the relative importance of production and ecohydrologic risks for each location and the most convenient crop systems to minimize their tradeoff.

Late-summer crops resulted the most convenient option to minimize production risk. Although an earlier sowing of summer crops could allow the expression of a higher yield potential and lower drainage rates in sites or years of adequate water offer, the likely combination of very high temperatures and negative water balance during the most critical period commonly reduce attainable yields of early sown summer crops 
(Maddonni, 2012). We found that the relative advantage of a later sowing prevailed into most of the semiarid Chaco, except in the most stressing areas (Water Stress Index >0.5) where no difference in yield was found. This agrees with other works (Houspanossian $e t$ $a l$. , submitted this issue) and with recent tendencies in farming choices that delay maize sowing to December - early January even though earlier sowing dates are recognized to have higher potential yields (Calviño and Monzón, 2009; Vega, 2011; Maddonni, 2012). Accordingly, within a sowing window for soybean that ranges from September to January, mid December sowings, a time in which soil water recharge has already occurred, are the most common choice (Calviño and Monzón, 2009). Consistently with their high production risk, spring crop systems are less frequent in the region. Sunflower (most common spring crop), is mainly confined to the central-east part of the region where the onset of the rainy season occurs earlier (Hall, et al., 2013). Still far from their potential, sunflower simulated yields in that area are acceptable when soil recharge in August is plenty and early spring rainfall allows sowing (Mercau, 2010). Hydrologically, spring crops present relatively low drainage rates which can be further reduced by applying more intensive sunflower-maize double crop systems during highrainfall years (Hall, et al., 2013). The use of a winter crop with no other crop during the year is not a common strategy but wheat is frequently sown into a double crop scheme with soybean (Recatalá Boix and Zinck, 2008b). Although the winter component of the double crop system is exposed to a very high water stress, soil water recharge from rainfalls between wheat harvest and subsequent soybean determine that water stress of the summer component was slightly higher than that of a single summer crop (Calviño and Monzón, 2009). Besides the positive effect on reducing deep drainage (SaladoNavarro and Sinclair, 2009; Nosetto, et al., 2012), double crop systems contribute to generate the amount of stubble necessary for soil protection and direct evaporation 
reduction, while the winter component represents an additional cash input when no other crop system does (Calviño and Monzón, 2009).

The choice conservative vs. intensive crop systems and its effect on production and deep drainage would depend on hydrological context and farmers perceptions. Besides the stochastic effect of the single year rainfall, the occurrence of consecutive wet years considerably boosts deep drainage fluxes. High residual soil water content after wet conditions or conservative crop systems in the previous year translates into a high initial soil water condition that contributes to the reduction of production risks (SaladoNavarro and Sinclair, 2009; Grassini, et al., 2010) but increases the probability of drainage (Grassini, et al., 2009). Conversely, crops are more likely to experience water stress after a dry year and/or a previous intensive crop system that left little residual soil water (Merrill, et al., 2007). In the absence of reliable rainfall forecasts, monitoring soil water content at the beginning of each season can be a useful tool to reduce the uncertainty in yearly water offer for the crop (Grassini, et al., 2010). The implementation of flexible cropping sequences that alternate conservative and intensive crop systems according to decision rules based on soil water recharge, greatly contributed to reduce drainage episodes in the most drainage-prone areas (4 vs. $52 \mathrm{~mm} . \mathrm{y}^{-}$ ${ }^{1}$ ) with little effects on production risk ( 17 vs. $7 \%$ water stress index). As soil water effects on subsequent crop yields and drainage vary from site to site and for different crop systems, soil water thresholds for decision rules should be determined locally. While our modeling approach allowed us to analyze the productive and environmental risk under wide geographical and agronomic scenarios (Yee Yet and Silburn, 2003), inaccuracies emerging from our model assumptions, parameterizations, simplifications, or choices of scale should be carefully considered (Gong, et al., 2012). In the productive aspect, it is encouraging that the areas and crop systems with lower water stress 
coincided with the location of major agriculture clusters and the most adopted crop strategies of the region, respectively (Calviño and Monzón, 2009; Clark, et al., 2010; Baldi, et al., 2014). The only cluster that does not follow this trend is the Mennonite colony area in the Paraguayan Chaco which is located in a high water stress area (Houspanossian, et al., submitted this issue). Remarkably, after years of poor agricultural performance, these colonies had to develop an economy based on intensive livestock systems based on pasture grazing (Glatzle, 2004). The model also seems to perform well in ecohydrologic terms. Not only did the model reproduce the expected response of drainage to the magnitude and temporal concentration of annual rainfall, but also its episodic nature and the synergistic effect of consecutive wet years (Keating, et al., 2002; Yee Yet and Silburn, 2003; Bah, et al., 2009; Bennett, et al., 2013). Moreover, clear drainage differences were detected among the analyzed crop systems as a result of their distinct growing season length and seasonality. These two characteristics, besides plants rooting depth, are the most relevant ecohydrologic parameters of vegetation covers (Asbjornsen, et al., 2008; Bah, et al., 2009; Santoni, et al., 2010; Nosetto et al., 2012). Consistently with other studies, our sensitivity analysis suggests that deeper rooting depth would not be as effective as growing season choice and surface cover/microtopography management in reducing drainage (Merrill, et al., 2007; Bah, et al., 2009). Simulations were much more sensitive to changes in crop systems and water gains/losses like runoff and fallow evaporation than to changes in total soil water storing capacity which is the pathway through which rooting depth will influence crop evapotranspiration. So, if more accurate simulations are aimed, efforts must be directed to a better characterization of direct evaporation and runoff processes across the area. Interestingly, some of the simulated crop systems can be assembled with crop species of contrasting quantity and quality of stubble, such as soybean and maize, which would 
have different effects on soil water evaporation and runoff fluxes (Monzon, et al., 2006; Grassini, et al., 2010; Salado-Navarro, et al., 2013). In this sense, emphasis should be put into the assessment of this additional diversity of agricultural strategies which would have a great impact on production and ecohydrologyc risks into the semiarid Chaco.

Salt leaching and increments in saline groundwater table levels as a result of dry forest clearing and its replacement with crop and livestock systems has been reported in sparse zones within and nearby the region, emphasizing the need to understand the ecohydrologic consequences brought up by changes in vegetation cover (Nitsch, 1995; Jobbágy, et al., 2008; Santoni, et al., 2010; Jayawickreme et al., 2011; Amdan, et al., 2013). To our knowledge, this is the first regional approach to the problem that focuses on the variation that different agricultural systems can introduce. Future works could enhance this analysis by including other farming systems, such as perennial pastures or woody species more similar in phenology to the native system, as alternatives to improve hydrological coupling in the most drainage-prone areas (Hatton and Nulsen, 1999). The ecohydrologic hazard, however, could be more serious and widespread than the depicted in our simulations. In Loma Plata, Paraguay (22.4S 59.8W) where the model estimates null drainage for any of the crop systems, salt leaching and the onset of groundwater recharge was evidenced at a regional level by water table level raises and the emergence of saline seeps (Nitsch, 1995). In soybean stands in eastern Salta, Argentina (24.5S 63.5W) Amdan et al. (2013) based on field evidence estimated drainage rates higher than ours $\left(27-87 \mathrm{~mm} \cdot \mathrm{y}^{-1}\right.$ during the last 3 decades $v s .12 \mathrm{~mm} \cdot \mathrm{y}^{-1}$ for modeled late-summer crops), yet, this was not the case in Bandera, Argentina (28.9S 62.2W, unpublished data) where our own on-field drainage estimates in paddocks of 20 to $>40$ years of agriculture $\left(3-19 \mathrm{~mm} \cdot \mathrm{y}^{-1}\right)$ are closer to those modeled here $(0$ and 18 
$\mathrm{mm} . \mathrm{y}^{-1}$ for summer and late summer crops, respectively). Groundwater rising around Loma Plata might be consequence of preferential drainage fluxes in focal spots occurring at a very local scale that were ignored by our simulations. Relatively low areas together with artificial infiltration dams (Magliano et al. et al., submitted this issue) or natural paleo-river beds of coarse texture, frequent in the zone, could present higher infiltration rates and collect water not only from rainfall but from runoff from adjacent areas (Larroza and Centurión, 1995; Tymkiw, 2010). Differential effects of stubble reducing evaporation under no-till systems in wetter areas would also be a source of error (Monzon, et al., 2006). As water losses increase exponentially with rainfall amount and concentration (Keating, et al., 2002; Yee Yet and Silburn, 2003), hydrologic simulation errors are likely to be higher in wetter and more seasonal areas like eastern Salta, than in Bandera.

\section{Conclusion}

The implementation of flexible cropping sequences that alternate conservative and intensive crop systems according to decision rules based on locally developed soil water thresholds is promising for managing the tradeoffs between production and ecohydrologic risks in the semiarid Chaco. The simulation approach employed in this study was useful not only to geographically assess this tradeoff under different crop systems, but also to understand current cultivation schemes and their geographical distribution. In the temporal dimension, this work illustrates that besides the effect of high-rainfall years on draining surplus, the occurrence of wet periods of more than one year have also an effect on drainage through their imprint on residual soil water being transferred from one year to the next. In this sense, initial soil water content appears as a useful indicator of the system state in relation to both productive and ecohydrologic 
objectives, which could aid farmers in their management decisions. Finally, this work complements and enhances the utility of more precise ecohydrologic measurements in the region, which given their limited spatial and temporal range are difficult to extrapolate at larger scales.

\section{Acknowledgements}

This work was funded by grants from the International Research Development Center (IDRC-Canada, Project 106601-001), from Agencia Nacional de Promoción Científica y Tecnológica ANPCyT (PRH 27 PICT 2008-00187), and from Inter American Institute for Global Change Research (IAI-CRN 3095) which is supported by the U.S. National Science Foundation (BIO-0717191). We would like to thank Germán Baldi for his help during the preparation and correction of the manuscript. 


\section{References}

Allen, R.G., Pereira, L.S., Raes, D., Smith, M., 1998. Crop evapotranspiration: guidelines for computing crop water requirements. FAO, Irrigation and Drainage Paper 56 , Rome.

Amdan, M.L., Aragón, R., Jobbágy, E.G., Volante, J.N., Paruelo, J.M., 2013. Onset of deep drainage and salt movilization following forest clearing and cultivation in the Chaco plains (Argentina). Water Resour. Res. 49, 6601-6612.

Asbjornsen, H., Shepherd, G., Helmers, M., Mora, G., 2008. Seasonal patterns in depth of water uptake under contrasting annual and perennial systems in the Corn Belt Region of the Midwestern U.S. Plant Soil 308, 69-92.

Bah, A.R., Kravchuk, O., Kirchhof., G., 2009. Sensitivity of drainage to rainfall, vegetation and soil characteristics. Comput. Electron. Agric. 60, 1-8.

Baldi, G., Houspanossian, J., Murray, F., Rosales, A.A., Rueda, C.V., Jobbágy E.G., 2014. Cultivating the dry forests of South America: Diversity of land users and imprints on ecosystem functioning. J. Arid Environ. DOI:10.1016/j.jaridenv.2014.05.027.

Bennett, S.J., Bishop, T.F.A., Vervoort, R.W., 2013. Using SWAP to quantify space and time related uncertainty in deep drainage model estimates: A case study from northern NSW, Australia. Agric. Water Manage. 130, 142-153.

Boletta, P.E., Ravelo, A.C, Planchuelo, A.M., Grilli, M., 2006. Assessing deforestation in the Argentine Chaco. For. Ecol. and Manage. 228, 108-114.

Calviño, P.A. Monzon, J.P., 2009. Farming systems of Argentina: yield constraints and risk management. In: Sadras, V.O., Calderini, D.F. (Eds.), Crop Physiology: Applications for Genetic Improvement and Agronomy. Academic Press, San Diego, pp. $55-70$. 
Caviglia, O.P., Andrade, F.H., 2010. Sustainable intensification of agriculture in the Argentinean Pampas: capture and use efficiency of environmental resources. Americas J. Plant Sci. Biotech. 3 (Special Issue), 1-8.

Caviglia, O.P., Sadras, V.O., Andrade, F.H., 2013. Modelling long-term effects of cropping intensification reveals increased water and radiation productivity in the Southeastern Pampas. Field Crop. Res. 149, 300-311.

Clark, M.L., Aide, T.M., Grau, H.R., Riner, G., 2010. A scalable approach to mapping annual land cover at $250 \mathrm{~m}$ using MODIS time series data: a case study in the Dry Chaco ecoregion of South America. Remote Sens. Environ. 114, 2816-2832.

Connor, D.J., Loomis, R.S., Cassman, K.G., 2011. Agricultural systems. In: Crop Ecology: Productivity and management in agricultural systems. Cambridge Univ Press. Pp: 358-383.

Dardanelli, J., Severina, I., Andriani, J., 2010. Funcionalidad de raíces y agua del subsuelo: Su rol en la optimización del riego suplementario. In: 1er Seminario Internacional de Riego en Cultivos y Pasturas. Potencial del riego extensivo en cultivos y pasturas. Pp: 19-28.

Dardanelli, J.L., Bachmeier, O.A., Sereno, R., Gil, R., 1997. Rooting depth and soil water extraction patterns of different crops in a silty loam Haplustoll. Field Crop. Res. $54,29-38$.

Díaz-Ambrona, C.G.H., O`Leary, G.J., Sadras, V.O., O`Connell, M.G., Connor, D.J., 2005. Environmental risk analysis of farming systems in a semi-arid environment: effect of rotations and management practices on deep drainage. Field Crop. Res. 94, $257-271$. 
George, R., McFarlane, D., Nulsen, B., 1997. Salinity threatens the viability of agriculture and ecosystems in Western Australia. Hydrogeology Journal 5, 6-21.

Glatzle A., Stosiek, D., 2002. Country pasture/forage resource profile of Paraguay. FAO. Rome, Italy.

Glatzle, A., 2004. Sistemas Productivos en el Chaco Central Paraguayo: Características, Particularidades. INTTAS, Loma Plata, Paraguay.

Gong, H., Pan, Y., Xu, Y., 2012. Spatio-temporal variation in groundwater recharge in response to variability in precipitation, land use and soil in Yanqing Basin, Beijing, China. Hydrogeol. J. 20, 1331-1340.

Grassini; P., Hall, A.J., Mercau, J.L., 2009. Benchmarking sunflower water productivity in semiarid environments. Field Crop. Res. 110, 251-262.

Grassini, P., You, J., Hubbard, K.G., Cassman, K.G., 2010. Soil water recharge in a semi-arid temperate climate of the Central U.S. Great Plains. Agric. Water Manage. 97, 1063-1069.

Grau, H.R., Gasparri, N.I., Aide, T.M., 2005. Agriculture expansion and deforestation in seasonally dry forests of north-west Argentina. Environ. Conserv. 32, 140-148.

Gregory, P.J., Ingram J.S.I., Andersson, R., Betts, R.A., Brovkin, V., Chase, T.N., Grace, P.R., Gray, A.J., Hamilton, N., Hardy, T.B., Howden, S.M., Jenkins, A., Meybeck, M., Olsson, M., Ortiz-Monasterio, I., Palm, C.A., Payn, Rummukainen, M., Schulze, R.E., Thiem, M., Valentin, C., Wilkinson, M.J., 2002. Environmental consequences of alternative practices for intensifiying crop production. Agric. Ecosyst. Environ. 88, 279-290. 
Hall, A.J., Feoli, C., Ingaramo, J., Balzarini, M., 2013. Gaps between farmer and attainable yields across rainfed sunflower growing regions of Argentina. Field Crop. Res. 143, 119-129.

Hanson, J.D., Liebig M.A., Merrill, S.D., Tanaka, D.L, Krupinsky, J.M., Stott, D.E., 2007. Dynamic cropping systems: increasing adaptability amid an uncertain future. Agron. J. 99, 939-943.

Hatton, T.J., Nulsen, R.A., 1999. Towards acieving functional ecosystem mimicry with respect to water cycling in southern Australian agriculture. Agrofor. Syst. 45, 203-214. Houspanossian, J., Giménez, R., Mercau, J.L., Baldi, G., Nosetto, M.D., Current and potential deforestation as a function of agricultural suitability. J. Arid Environ. (submitted) Jayawickreme, D.H., Santoni, C.S., Kim, J.H., Jobbágy, E.G., Jackson, R.B., 2011. Changes in hydrology and salinity accompanying a century of agricultural conversion in Argentina. Ecol. Appl. 21, 2367-2379.

Jobbágy, E.G., Nosetto, M.D., Santoni, C.S., Baldi, G., 2008. El desafío ecohidrológico de las transiciones entre sistemas leñosos y herbáceos en la llanura Chaco-Pampeana. Ecol. Austral 18, 305-322.

Keating, B.A., Gaydon, D., Huth, N.I., Probert, M.E., Verburg, K., Smith, C.J., Bond, W., 2002. Use of modelling to explore the water balance of dryland farming systems in the Muray-Darling Basin, Australia. Eur. J. Agron. 18, 159-169.

Kropff, M.F., Bouma, J., Jones, J.W., 2001. System approaches for the design of sustainable agro-ecosystems. Agric. Syst. 70, 369-393. 
Larroza, F.A., Centurión, C., 1995. Estudio hidrogeológico e hidroquímico del agua freática en el área urbana de Loma Plata, Chaco Paraguayo. Dirección de Recursos Hídricos, Filadelfia, Paraguay.

Maddonni, G., 2012. Analysis of the climatic constraints to maize production in the current agricultural region of Argentina - a probabilistic approach. Theor. Appl.

Climatol. 107, 325-345.

Magliano, P.N., Murray, F., Baldi, G., Aurand, S., Harder, W., Jobbágy, E.G., Rainwater harvesting in the Dry Chaco: Evolving strategies and challenges. J. Arid Environ. (submitted)

Mercau, J.L., 2010. El agua y la temperatura como limitantes del rendimiento de girasol bajo planteos de alta tecnología en el NEA. Asociación Argentina de Girasol, ASAGIR, Buenos Aires, Argentina. Pp. 20.

Merrill, S.D., Tanaka, D.L., Krupinsky, J.M., Liebig, M.A., Hanson, J.D., 2007. Soil wáter depletion and recharge under ten crop species and applications to the principles of Dynamic Cropping Systems. Agron. J. 99, 931-938.

Minetti, J.L., 1999. Atlas Climático del Noroeste Argentino. Laboratorio Climatológico Sudamericano, Fundación Zona Caldenius, Tucumán, Argentina.

Monzon, J.P., Sadras, V.O., Andrade, F.H., 2006. Fallow soil evaporation and water storage as affected by stubble in sub-humid (Argentina) and semi-arid (Australia) environments. Field Crop. Res. 98, 83-90.

National Land and Water Resources Audit., 2001. Australian Dryland Salinity Assessment 2000, National Land and Water Resources Audit, Canberra.

New, M., Lister, D., Hulme, M., Makin, I., 2002. A high-resolution data set of surface climate over global land areas. Clim. Res. 21, 1-25. 
Nitsch, M., 1995. El desmonte en el Chaco Central del Paraguay, influencia sobre el agua subterránea y la salinización de suelos. 2do simposio sobre aguas subterráneas y perforación de pozos en el Paraguay. San Lorenzo, Paraguay, 75-86.

Nix, H.A., Fitzpatrick, E.A., 1969. An index of crop water stress related to wheat and grain sorghum yields. Agric. Meteorol. 6, 321-337.

Nosetto, M.D., Jobbágy, E.G., Brizuela, A.B., Jackson, R.B., 2012. The hydrologic consequences of land cover change in central Argentina. Agric. Ecosyst. Environ. 154, $2-11$.

Olson, D.M., Dinerstein, E., Wikramanayake, E.D., Burgess, N.D., Powell, G.V.N.,Underwood, E.C., et al., 2001. Terrestrial ecoregions of the world: a new map oflife on earth. BioScience 51, 933-938.

Pannell, D.J., 2001. Dryland salinity: economic, scientific, social and policy dimensions. Aust. J. Agr. and Resour. Econ. 45, 517-546.

Pannell, D.J., Ewing, M.A., 2006. Managing secondary dryland salinity: Options and challenges. Agric. Water Manage. 80, 41-56.

QGIS Development Team., 2013. QGIS Geographic Information System. Open Source Geospatial Foundation Project. http://qgis.osgeo.org

Ray, J.D., Gesch, R.W., Sinclair, T.R., Hartwell Allen, L., 2002. The effect of vapor pressure deficit on maize transpiration response to a drying soil. Plant Soil 239, 113 121.

Recatalá Boix, L, Zinck, J.A., 2008a. Land-use planning in the Chaco Plain (Burruyacú, Argentina). Part 1: Evaluating Land-use options to support crop diversification in an agricultural frontier area using physical land evaluation. Environ. Manage. 42, 10431063. 
Recatalá Boix, L, Zinck, J.A., 2008b. Land-use planning in the Chaco Plain (Burruyacú, Argentina). Part 2: Generating a consensus plan to mitigate land-use conflicts and minimize land degradation. Environ. Manage. 42, 200-209.

Riveros, F., 2003. The Gran Chaco. FAO Bulletin. Rome, Italy. Available at: www.fao.org/ag/AGP/AGPC/doc/Bulletin/granchaco.htm (last accessed: 26 Nov 2013)

Sadras, V.O., Roget, D.K., 2004. Production and environmental aspects of cropping intensification in a semiarid environment of southeastern Australia. Agron. J. 96: 236246.

Sadras, V., Roget, D., Krause, M., 2003. Dynamic cropping strategies for risk management in dry-land farming systems. Agric. Syst. 76, 929-948.

Salado-Navarro, L.R., Sinclair, T.R. 2009., Crop rotations in Argentina: Analysis of water balance and yield using crop models. Agric. Syst. 102, 11-16.

Salado-Navarro, L.R., Sinclair, T.R, Morandini, M., 2013. Estimation of soil evaporation during fallow seasons to assess water balances for no-tillage crop rotations. J. Agron. Crop Sci. 199, 57-65.

Santoni, C.S., Jobbágy, E.G., Contreras, S., 2010. Vadose zone transport in dry forests of central Argentina: Role of land use. Water Resour. Res., 46, W10541.

Sinclair, T.R. 2005., Theoretical analysis of soil and plant traits influencing daily plant water flux on drying soils. Agron. J. 97, 1148-1152.

Tanaka, D.L., Krupinsky, J.M., Liebig, M.A., Merrill, S.D., Ries, R.E., Hendrickson, J.R., Johnson, H.A., Hanson J.D., 2002. Dynamic cropping systems: an adaptable approach to crop production in the Great Plains. Agron. J. 94, 957-961. 
Tymkiw, P.T., 2010. Estudio técnico de alternativas de abastecimiento de agua al Chaco

Central. Consultoría Internacional - Contrato BID 001. Asunción, Paraguay. Pp: 203.

Vega, C.R.C., 2011. Determinación del rendimiento de maíz ante modificaciones en el manejo de la densidad, distancia entre surcos y fecha de siembra. Análisis de campañas 2007-2010 de miembros de MAIZAR en el NOA. Buenos Aires, Argentina. 55pp.

Volante, J.N., Alcaraz-Segura, D., Mosciaro M.J., Viglizzo, E.F., Paruelo, J.M., 2012. Ecosystem functional changes associated with land clearing in NW Argentina. Agric. Ecosyst. Environ. 154, 12-22.

Yee Yet, J.S., Silburn, D.M., 2003. Deep drainage estimates under a range of land uses in the QMDB using water balance modelling. Department of Natural Resources and Mines, Queensland.

\section{Tables}

Table 1: Monthly crop coefficients (Kc) for the different crop systems studied in this work: W (winter), Sp (spring), S (summer), LS (late summer), DC (winter-summer double crop). Kc values for the critical period of yield determination in each system are highlighted. $\mathbf{f}$ stands for fallow Kc which are calculated separately, taking values from 0.1 to 1.15 .

\begin{tabular}{|c|c|c|c|c|c|c|c|c|c|c|c|c|}
\hline \multirow[b]{2}{*}{ Crop system } & \multicolumn{12}{|c|}{ Month } \\
\hline & $\mathbf{J}$ & $\mathbf{J}$ & A & $\mathbf{S}$ & 0 & $\mathbf{N}$ & D & $\mathbf{J}$ & $\mathbf{F}$ & $\mathbf{M}$ & A & $\mathbf{M}$ \\
\hline W & 0.2 & 0.4 & 0.7 & 1 & 1 & 0.3 & $f$ & $f$ & $f$ & $f$ & $f$ & $f$ \\
\hline Sp & $f$ & 0.2 & 0.2 & 0.5 & 0.8 & 1.1 & 1 & 0.3 & $f$ & $f$ & $f$ & $f$ \\
\hline$s$ & $f$ & $f$ & f & f & $f$ & $f$ & 0.45 & 0.7 & 1 & 1.1 & 0.7 & $f$ \\
\hline LS & $f$ & $f$ & $f$ & $f$ & $f$ & $f$ & $f$ & 0.45 & 0.7 & 1 & 1 & 0.5 \\
\hline DC & 0.2 & 0.4 & 0.7 & 1 & 1 & 0.3 & 0.45 & 0.7 & 1 & 1.1 & 0.7 & $f$ \\
\hline
\end{tabular}




\section{Figure Captions}

Figure 1: map of the study region (Olson, et al., 2001) and location of the five study cases analyzed in this work: Alto Paraguay (AP), Loma Plata (LP), Tartagal (TL), Tucumán (TM) and Bandera (BN). Striped areas are floodplains, water bodies or mountainous soils (leptosols) not considered in the analysis.

Figure 2: a) Water Stress Index (WSI); b) Water Deficit (crop evapotranspiration effective rainfall) during the critical period for yield determination $\left(\mathbf{W D}_{\mathbf{C P Y}}\right)$; c) Soil water content at the beginning of the critical period (AW $\mathbf{C P Y})$; d) Mean annual drainage (DR; mm.season $\left.^{-1}\right)$ and e) residual water content $\left(\mathbf{A} \mathbf{W}_{\text {res }}\right)$ for a summer crop system $(\mathbf{S})$ in the semiarid Chaco region.

Figure 3: a) Water Stress Index (WSI); b) Water Deficit (crop evapotranspiration effective rainfall) during the critical period for yield determination (WD $\left.\mathbf{W P Y}_{\mathbf{C P Y}}\right)$; c) Soil water content at the beginning of the critical period (AW $\mathbf{C P Y})$; d) Mean annual drainage (DR; mm.season $\left.{ }^{-1}\right)$ and e) residual water content $\left(\mathbf{A W}_{\text {res }}\right)$ for different cropping systems (W: winter; Sp: Spring; LS: late summer and DC: double-crop, a summer crop following a winter crop in the same growing season) as related to the same parameters of a summer crop system (S) in the semiarid Chaco region. In a) and c) only WSI and $\mathbf{A} \mathbf{W}_{\mathbf{C P Y}}$ for the summer component of $\mathbf{D C}$ system are presented; In b) $\mathbf{W D}_{\mathbf{C P Y}}$ for $\mathbf{D C}$ system is not presented because is similar to that of $\mathbf{W}$ (for the winter component) and to $\mathbf{S}$ (for the summer component). 
Figure 4: Cumulative drainage (1959-2002) of three crop systems $\mathbf{S}$ (summer), LS (late-summer) and DC (double crop) in relation to annual rainfall and initial soil water content $\left(\mathbf{A W}_{\text {ini) }}\right)$ in four sites of interest: Tartagal (TL), Tucumán (TM), Bandera (BN) and Loma Plata (LP).

Figure 5: Water Stress Index (WSI) and mean annual drainage of three crop systems (S: summer; LS: late summer; DC: winter-summer double crop) in relation to initial soil water content (1-Jun), in five sites of interest. WSI of DC is represented separately for its two constituent components: winter crop $\left(\mathbf{D C}_{\mathbf{W}}\right)$ and summer crop $\left(\mathbf{D C}_{\mathbf{S}}\right)$. Lines represent non-linear model fits for mean WSI (complete) and for mean annual drainage (dashed).

Figure 6: a) Mean Water Stress Index (WSI) and b) Mean annual drainage (Dr; mm.season ${ }^{-1}$ ) for a flexible crop sequence (flex) as related to the same parameters of a continuous summer crop system $(\mathbf{S})$ in 3 subzones of the semiarid Chaco varying in rainfall amount/seasonality: $\mathrm{A}(\mathrm{P}=650-800$ or $\mathrm{P}>800$ and seasonality $<0.66), \mathrm{B}$ $\left(\mathrm{P}<650 \mathrm{~mm} \cdot \mathrm{yr}^{-1}\right)$ and $\mathrm{C}\left(\mathrm{P}>800 \mathrm{~mm} \cdot \mathrm{yr}^{-1}\right.$; seasonality $\left.>0.66\right)$. Note that WSI of the winter component of DC systems was not considered for mean WSI computation.

Figure 7: Mean Water Stress Index (WSI; a, b, c) and Mean annual drainage (Dr; mm.season $\left.{ }^{-1} ; \mathbf{d}, \mathbf{e}, \mathbf{f}\right)$ for a summer crop system $(\mathbf{S})$ resulting from an increase $(+50 \%)$ or a decrease $(-50 \%)$ in some of the model inputs: Runoff (mm; a and d), fallow 
evaporation ( $\mathrm{mm} ; \mathbf{b}$ and $\mathbf{e})$ and $\mathbf{A W m a x}$ (maximum available water; $\mathrm{mm}$; $\mathbf{c}$ and $\mathbf{f}$ ). The abbreviation "mod" stands for outputs of the modified model. 


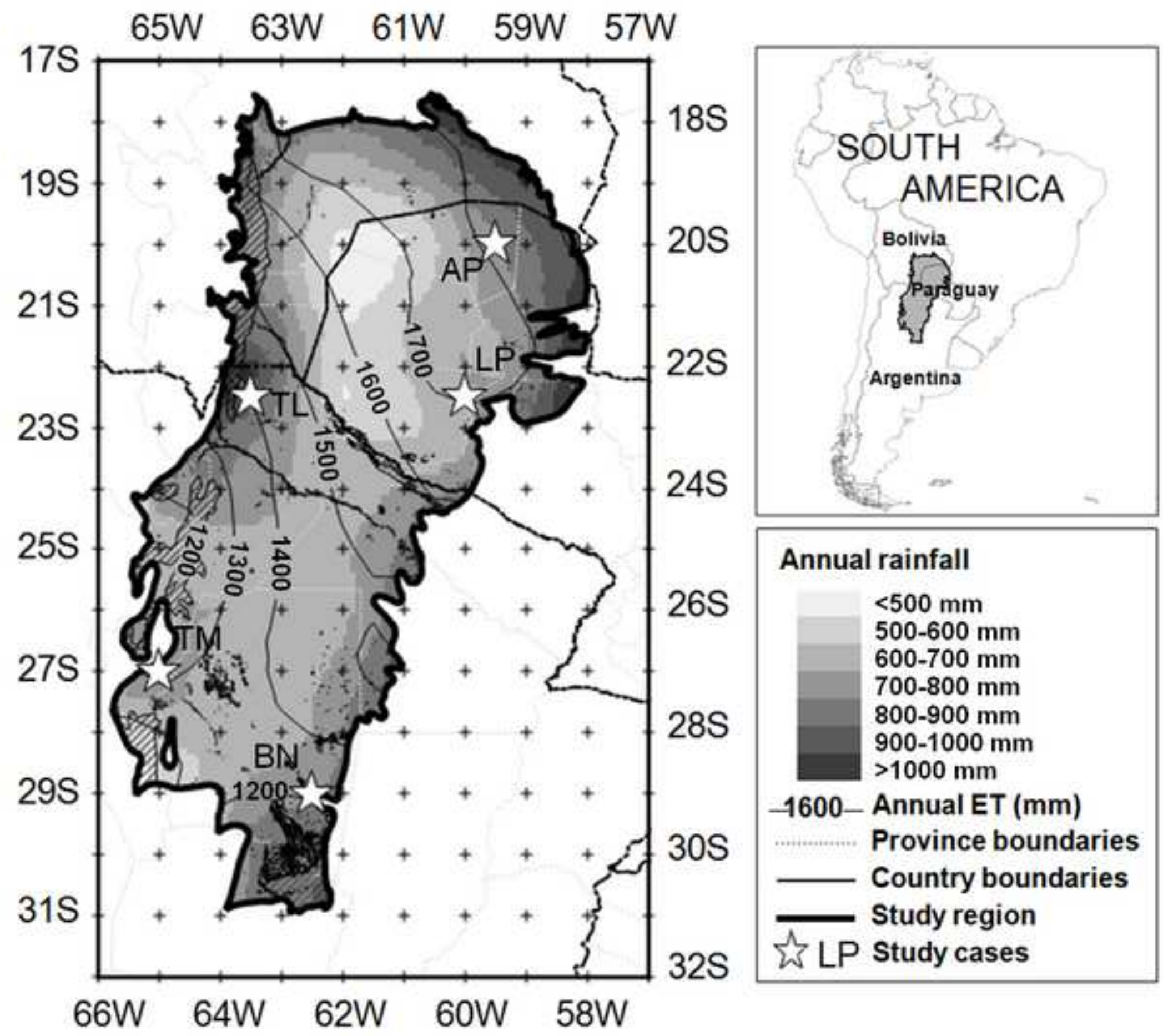



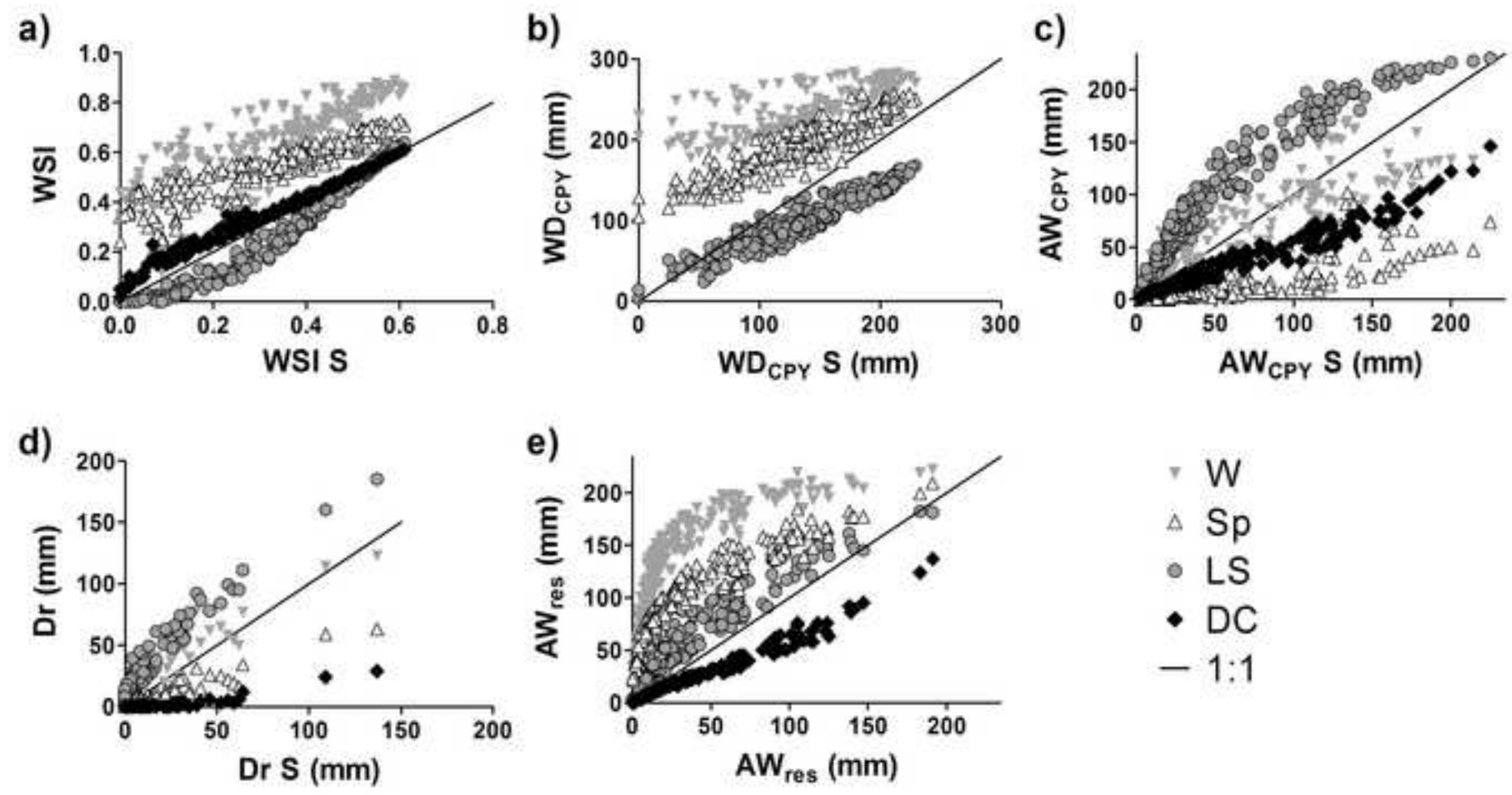
a)

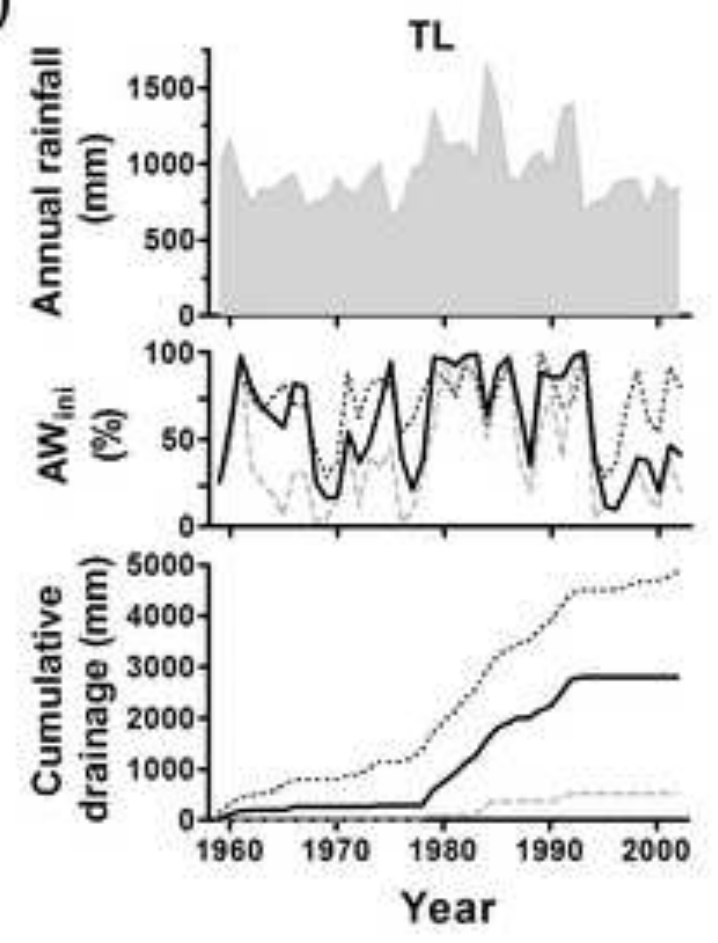

c)

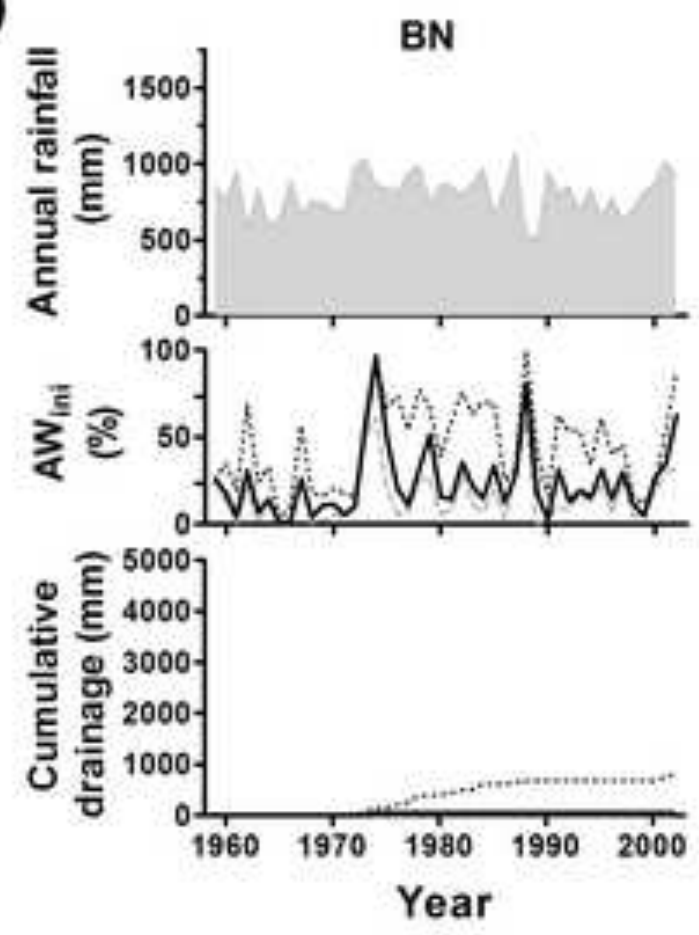

b)

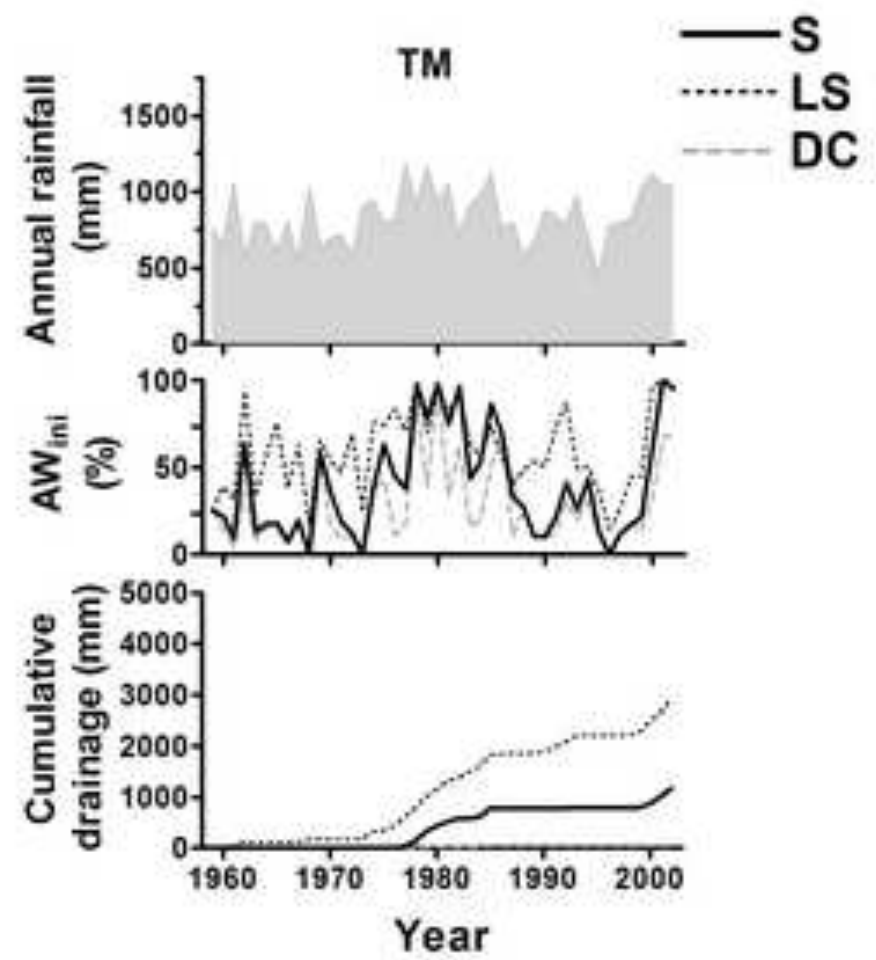

d)

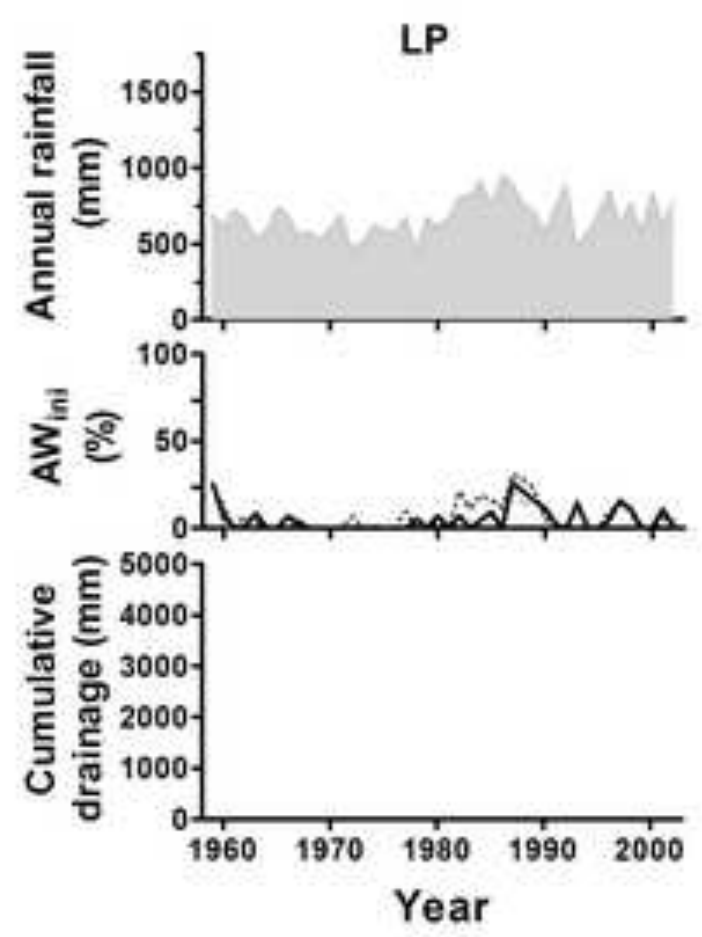


a)

AP

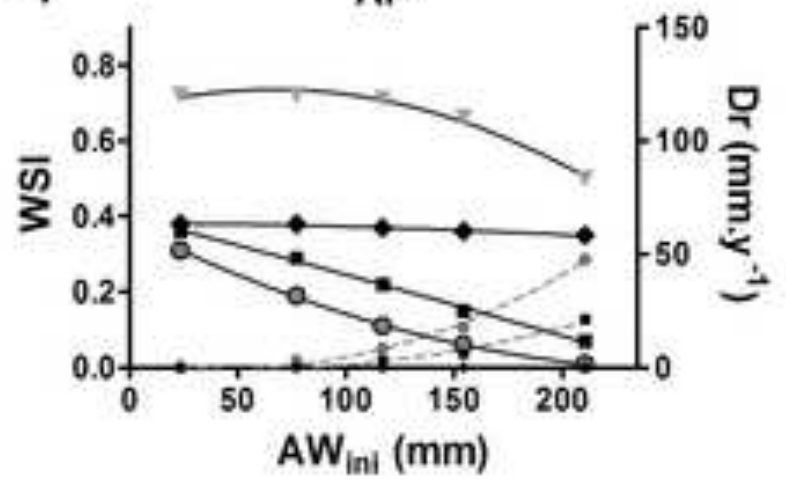

d)

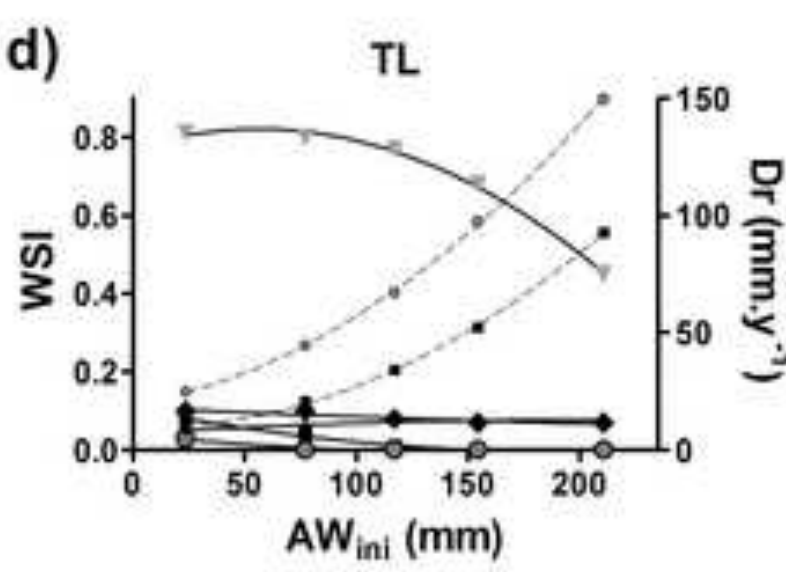

b)

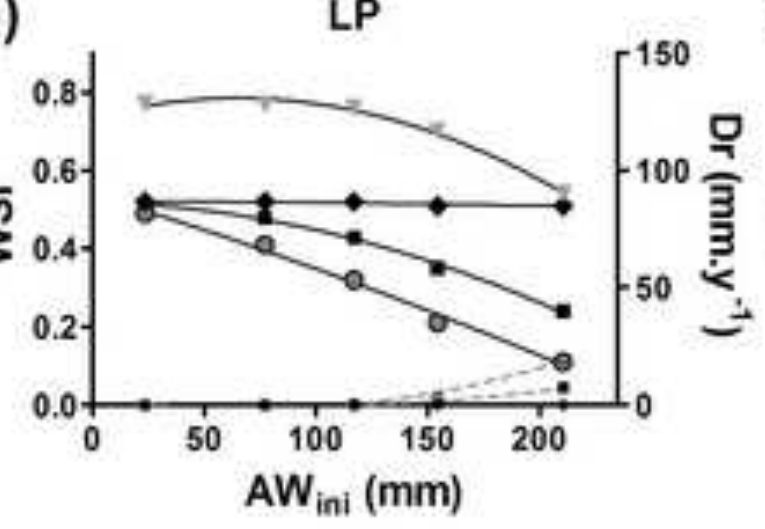

e)

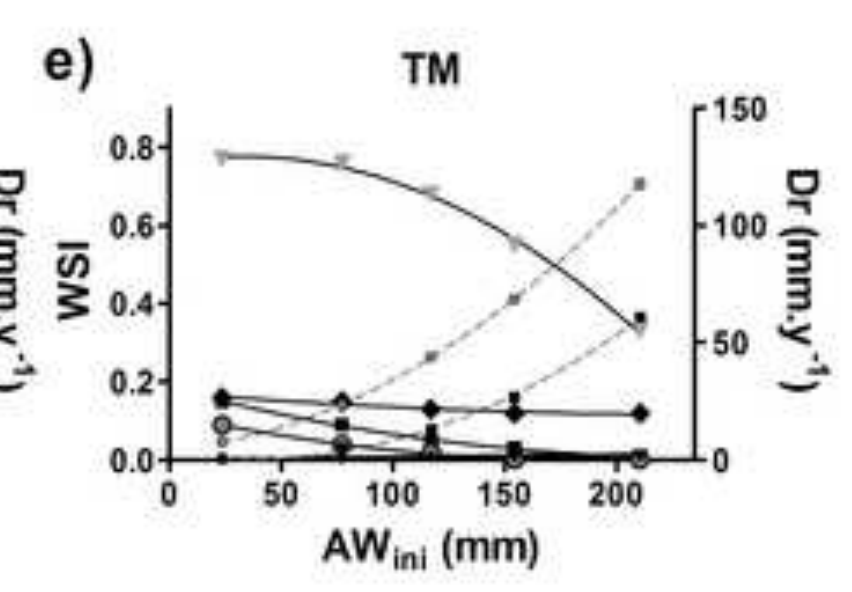

c)

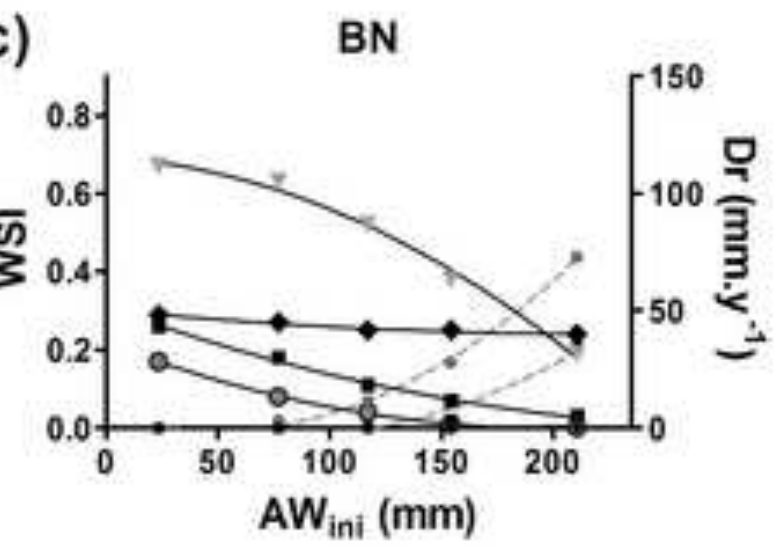

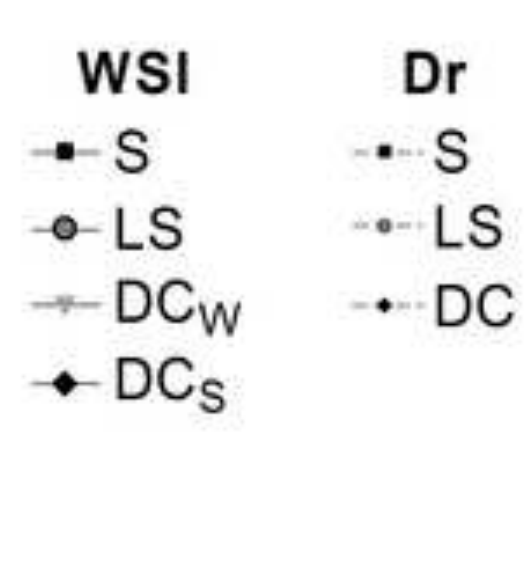



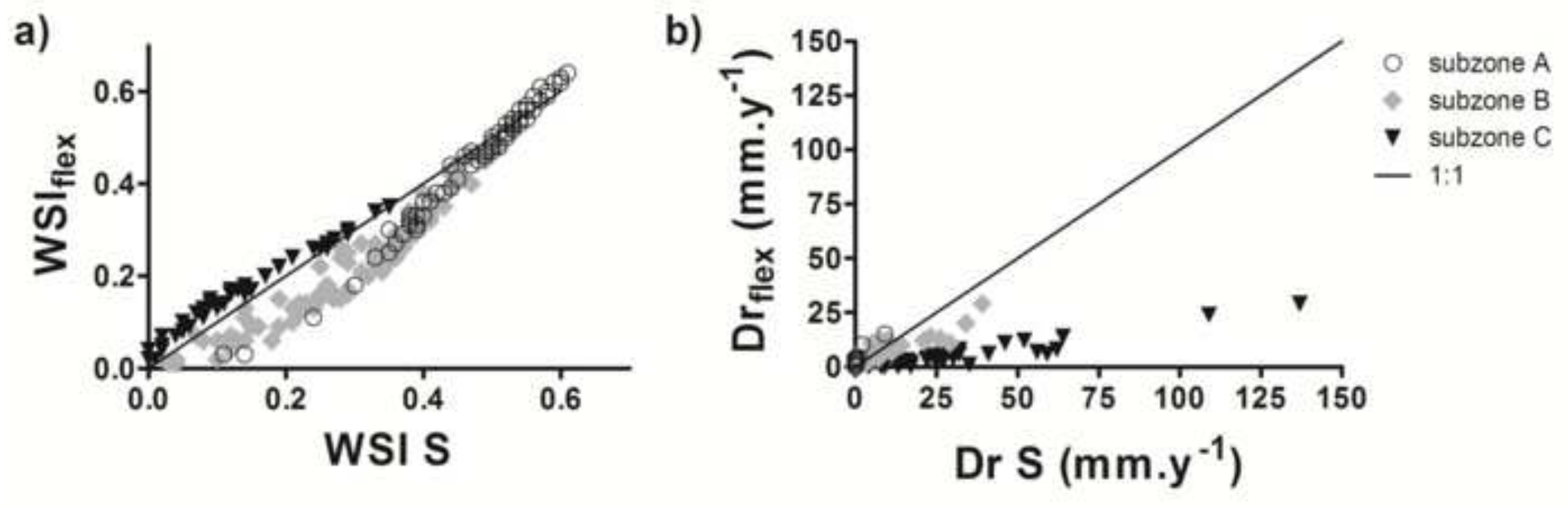
a)

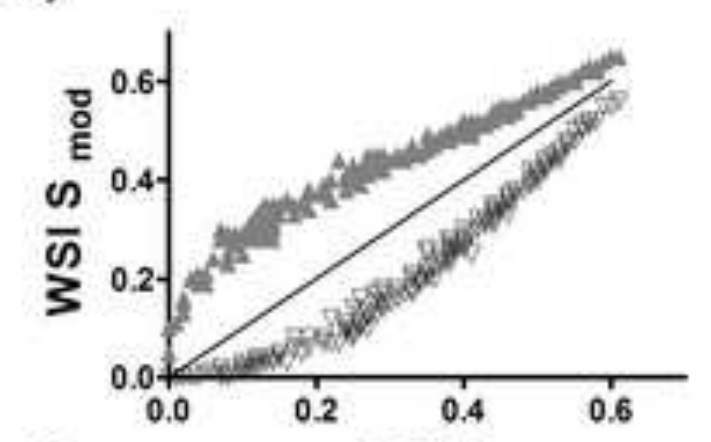

d)

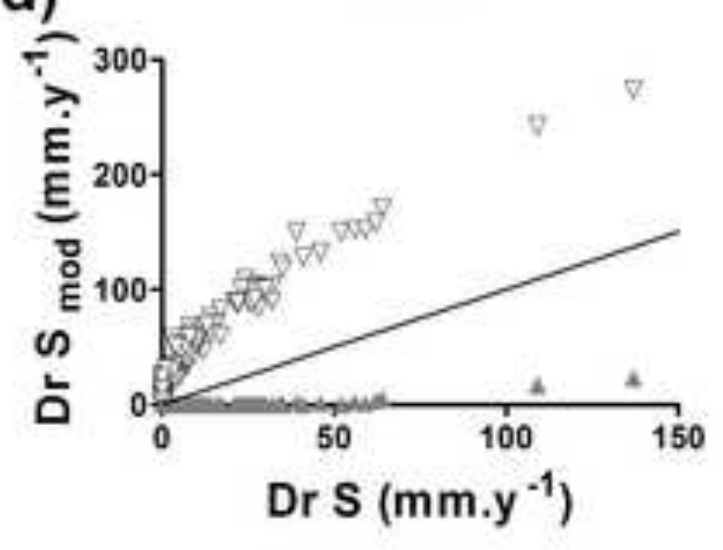

b) Fallow evaporation

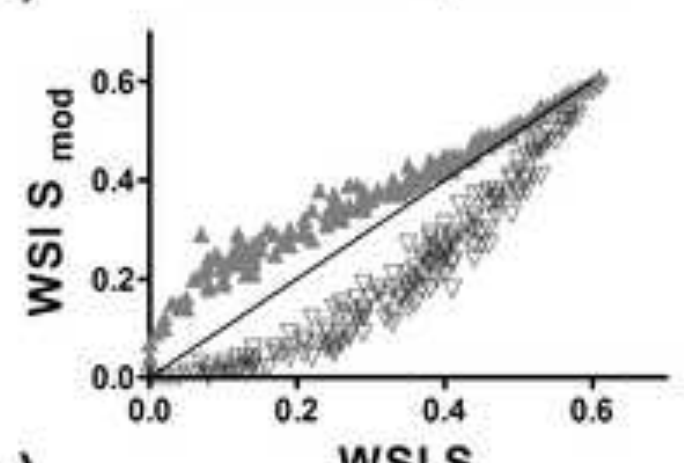

e)

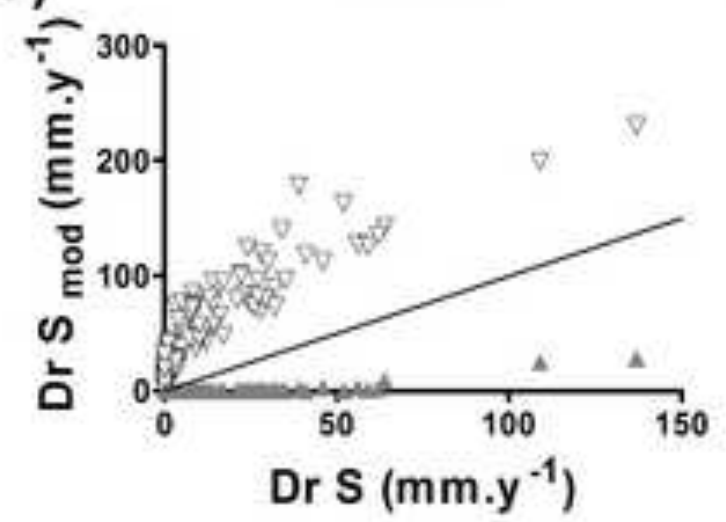

c) Maximum soil water

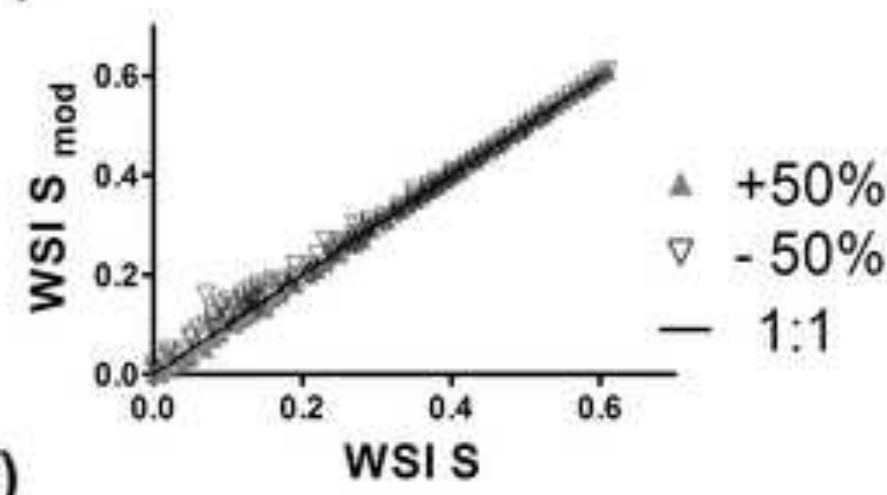

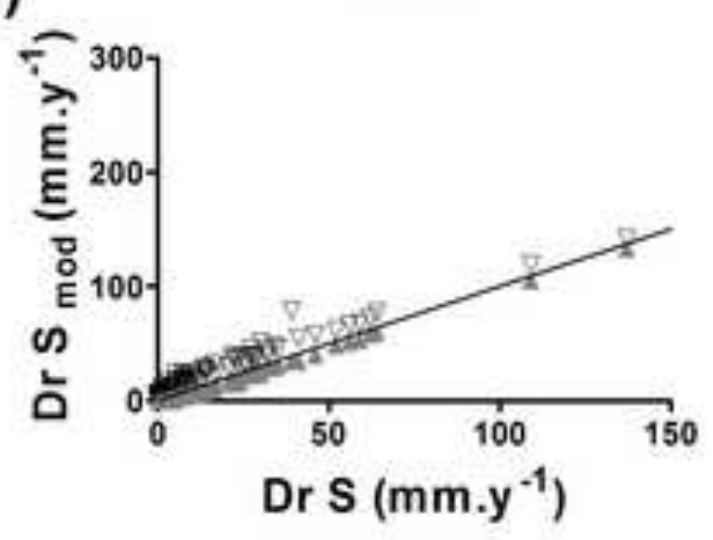

